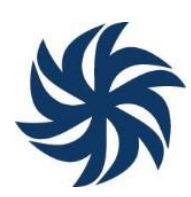

\title{
PERFORMANCE ELEITORAL DOS PARLAMENTARES E ALOCAÇÃO DE RECURSOS NOS MUNICÍPIOS: EFEITO DOS DISTRITOS INFORMAIS
}

\author{
ELECTORAL PERFORMANCE OF PARLIAMENTARIANS AND ALLOCATION OF \\ RESOURCES IN MUNICIPALITIES: EFFECT OF INFORMAL DISTRICTS
}

\section{DESEMPEÑO ELECTORAL DE LOS PARLAMENTARIOS Y ASIGNACIÓN DE RECURSOS EN LOS MUNICIPIOS: EFECTO DE LOS DISTRITOS INFORMALES}

\author{
Kelly Cristina Costa Soares ${ }^{1}$ \\ Allan Gustavo Freire da Silva ${ }^{2}$ \\ Palloma Farias do Nascimento ${ }^{3}$ \\ José João Correia de Oliveira Filho ${ }^{4}$
}

\begin{abstract}
Resumo: Esta pesquisa busca investigar qual o efeito produzido pela votação dos deputados federais eleitos nos estados da Paraíba e Pernambuco, e seu comportamento relativo à apresentação e execução de emendas. Os dados foram coletados nos bancos do Tribunal Superior Eleitoral - TSE (eleições gerais do Brasil de 2014) e a respectiva legislatura, utilizando dados das emendas apresentadas pelos referidos parlamentares nos anos de 2016, 2017 e 2018, dados disponíveis no banco Siga Brasil do Senado Federal. Por meio de estatística descritiva, o estudo possibilitou expor um panorama do perfil dos deputados e suas atuações em relação à apresentação de emendas. Tais análises consideram que a distinção entre emendas direcionadas a municípios e aos estados, em sua totalidade, pode estar associada ao padrão de distribuição de votos obtidos pelos deputados.
\end{abstract}

Palavra-chave: Emendas; Legislatura; Deputados; Votos.

Abstract: This research seeks to investigate the effect produced by the vote of federal deputies elected in the states of Paraíba and Pernambuco, and their behavior regarding the presentation and execution of amendments. The data were collected in the date base of the Superior Electoral Court - TSE - 2014 and the respective legislature, using data from the amendments submitted by the referred parliamentarians in the years 2016, 2017 and 2018, data available in the sata base Siga Brasil of the Federal Senate. Through descriptive statistics, the study made it possible to expose an overview of the deputies' profile and their actions in relation to the presentation of

\footnotetext{
${ }^{1}$ Professora e Pesquisadora do Programa de Pós-Graduação em Ciência Política da UFCG. Possui graduação em Ciências Sociais pela Universidade Federal do Rio Grande do Norte (1997), mestrado em Sociologia pela Universidade Federal de Pernambuco (2000) e doutorado em Ciência Política pela Universidade Federal de Pernambuco (2010). E-mail: kelsoares2016@uol.com.br. ORCID ID: http://orcid.org/0000-0003-3129-231X.

${ }^{2}$ Doutorando em Administração (2019) pela Universidade Potiguar (UnP), Mestre em Desenvolvimento Regional (2016) pela Universidade Estadual da Paraíba (UEPB), Especialista em Gestão Pública (2015) pela Faculdade Internacional Signorelli (FISIG), Graduado em Gestão Pública (2014) pela Universidade Federal de Campina Grande (UFCG). É professor efetivo na Universidade Federal de Campina Grande, área de Administração Pública, no campus de Sumé - PB. E-mail: allangfs@ @otmail.com. ORCID ID: http://orcid.org/0000-0003-1550-8061.

3 Possui graduação em Letras pela Universidade Estadual da Paraíba (2014). Graduada no Curso Superior de Tecnologia em Gestão Pública, pela Universidade Federal de Campina Grande - UFCG. E-mail: pallomamyler@hotmail.com. ORCID ID: http://orcid.org/0000-0001-5048-5075.

${ }^{4}$ Mestre em Ciência Política pela Universidade Federal de Campina Grande (UFCG). Graduado em Direito pela Universidade Estadual da Paraíba (UEPB). Servidor Público da Assembleia Legislativa do Estado da Paraíba (ALPB) no cargo de Analista Legislativo. Atua no Departamento de Assistência às Comissões aonde desenvolve trabalho de análise prévia de constitucionalidade, juridicidade e mérito das proposições legislativas. E-mail: josejoaofilho@hotmail.com. ORCID ID: http://orcid.org/0000-0001-6787-4528.
} 
amendments. Such analyzes made it possible to consider that the distinction between amendments directed to municipalities and states, in their entirety, may be associated with the pattern of distribution of votes obtained by deputies.

Keywords: Amendments; Legislature; Deputies; Wishes.

Resumen: Esta investigación busca investigar el efecto producido por el voto de los diputados federales elegidos en los estados de Paraíba y Pernambuco, y su comportamiento con respecto a la presentación y ejecución de enmiendas. Los datos fueron recopilados en los bancos del Tribunal Superior Electoral - TSE - 2014 y la legislatura respectiva, utilizando datos de las enmiendas presentadas por los parlamentarios referidos en los años 2016, 2017 y 2018, datos disponibles en el banco Siga Brasil del Senado Federal. Mediante estadísticas descriptivas, el estudio permitió exponer una visión general del perfil de los diputados y sus acciones en relación con la presentación de enmiendas. Tales análisis permitieron considerar que la distinción entre enmiendas dirigidas a municipios y estados, en su totalidad, puede estar asociada con el patrón de distribución de votos obtenido por los diputados.

Palabras clave: Enmiendas; Legislatura Diputados; Votos.

\section{Introdução}

Há discussão consolidada na ciência política sobre a relação entre tipo de votação dos eleitos para o parlamento brasileiro e os incentivos criados para alocação de recursos aos estados e municípios através do dispositivo das emendas orçamentárias. Assim, é chamado o comportamento parlamentar e sua a conexão eleitoral e no campo de análises das instituições políticas brasileiras considera a existência de distritos informais, como resultado da combinação entre sistema eleitoral de lista aberta e representação proporcional (AMES, 2003).

A referência que se tem usado para embasar explicações sobre esse fenômeno empírico chamado distritos informais é tida pela averiguação entre a dominância eleitoral dos deputados em determinados municípios contíguos e seus esforços em alocar recursos para essas localidades através dos dispositivos das emendas orçamentárias.

Tendo em vista os aspectos do sistema eleitoral do Brasil que desagua no multipartidarismo, o jogo político vai sendo configurado por governos minoritários. A alternativa, para dissuadir os possíveis entraves no processo decisório, advém do reconhecimento por parte do Executivo que deve ampliar sua base parlamentar. Para tanto, a formação de coalizão torna-se condição sine qua non para a estabilidade política. A partilha de poder com os partidos passa por diversas estratégias, distribuição de pastas ministeriais e as emendas parlamentares ao orçamento do Executivo são consideradas importantes instrumentos de barganha na relação do Executivo com o Legislativo (BATISTA, 2017; ABRANCHES, 2018; AMORIM NETO, 2006; PEREIRA; MUELLER, 2004).

Bertholini e Pereira (2017) criaram um índice de custo do governo chamando atenção de pressupostos para eficiência do presidencialismo de coalizão. Conforme os autores, o tamanho da coalizão, a heterogeneidade ideológica e a alocação proporcional de poder entre 
partidos fazem diferença na performance da relação entre Executivo-Legislativo e especialmente na viabilidade de gerenciamento por parte do presidente.

Os cientistas políticos brasileiros muito têm debatido sobre as consequências das regras eleitorais e do sistema multipartidário no comportamento apresentado pelos parlamentares (NICOLAU, 2017). É importante lembrar que a literatura acerca desse tema está dividida entre os que afirmam que a acentuada dispersão de poder tem grande papel nas dificuldades institucionais pelas quais o país está passando e os defendem que essa dispersão apenas indica que o governo deverá ser de coalizão e não possui determinação da paralisia decisória. Para tanto, a importância dos partidos e dos líderes que fazem parte da coalizão indica as estratégias para composição de quadros no governo (ABRANCHES, 2018).

Desde a redemocratização do Brasil que os estudiosos da política se debruçam sobre a força do Poder Legislativo na execução dos planos do Poder Executivo. Com a Constituição de 1988, o parlamento assume um lugar importante de poder interferir no planejamento e alocação dos recursos públicos. Não obstante, mesmo obtendo esse ganho de poder, a forma de se relacionar com o poder Executivo determina essa influência.

Os estudos sobre os efeitos do multipartidarismo em países de reconstituição democrática como o Brasil apontam a saída para embates e conflitos entre Executivo e Legislativo. Assim foi chamado o Presidencialismo de coalizão, que numa articulação, o Executivo e Legislativo encontram incentivos para cooperação (ABRANCHES, 2018). A partir de então, o dispositivo constitucional que autoriza emenda individual ou coletiva permite que as relações entre o Executivo e o Legislativo sejam dadas com base no trade-off emendas e apoio parlamentar. Nesse sentido, as emendas ao orçamento do Executivo ocuparam lugar importante nos estudos sobre as relações entre Executivo-Legislativo e sobre desempenho eleitoral e seu poder de alocar recursos às suas bases eleitorais.

A observação das vantagens na votação que determinados deputados apresentam em determinados municípios são consideradas para denominar como os votos são distribuídos pelo território da unidade federativa. Assim, distribuição espacial do voto é o termo utilizado pela literatura em ciência política para identificar padrões de votação dos deputados.

A denominação distritos informais é utilizada por Ames (2003) para caracterizar dominação ou concentração de votos dos deputados em um município ou conjunto de munícipios contíguos. Nesse caso, apesar do sistema eleitoral brasileiro apresentar alta magnitude distrital, a votação dos deputados pode assumir uma distribuição que permite identificar redutos.

Com o intuito de adotar as teorias que discorrem sobre o comportamento parlamentar e conexão eleitoral essa pesquisa busca investigar qual o efeito produzido pela votação dos deputados federais eleitos (2014-2018) nos estados da Paraíba e Pernambuco e seu comportamento relativo à apresentação e execução de emendas. A escolha e delimitação do 
campo empírico justificam-se por se tratar de estados vizinhos pertencentes à mesma região, condições socioeconômicas e cultura política, mas com particularidades em relação à quantidade e tamanho dos municípios, detalhes estão apresentados na metodologia. Assim, buscou-se explicar a partir do método comparado, semelhanças e diferenças na distribuição do voto e no empenho dos parlamentares para alocar recursos aos municípios e ao estado em sua total dimensão territorial.

O estado da Paraíba possui 223 municípios, enquanto Pernambuco possui número menor 185, no entanto, os municípios paraibanos são em grande parte pequenos em termos populacionais e eleitorais. Nesse sentido, a distribuição do voto dos deputados se mostrou diferente nos dois estados. Para os deputados paraibanos a busca por votos deve-se a maiores esforços para maximização de sua votação depende de penetração em muitos pequenos municípios. O sistema multipartidário resulta num mercado de alta competição para obtenção de sucesso eleitoral, resultando um tipo de votação dispersa-compartilhada. Nesse caso, exige-se dispêndio para percorrer todo o território do estado. O texto ora apresentado traz um recorte de uma pesquisa mais ampla que busca comparar o comportamento de deputados federais e estaduais que inclui outros estados no que concerne as suas vinculações com municípios.

O objetivo desta pesquisa busca investigar como vem sendo utilizado o dispositivo de emendas ao orçamento da União pelos deputados federais dos referidos estados. Para tanto, buscou-se averiguar de que modo se dá a variação entre emendas apresentadas e executadas e como a votação de cada deputado em cada município pode direcionar a alocação de recursos.

Os dados coletados também permitiram observar e interpretar como a distinção entre emendas direcionadas a municípios e ao estado em sua totalidade pode estar associada ao padrão de distribuição de votos dos deputados. A isso se entende que a identificação do peso dos municípios na alocação de recursos tem relação direta com vantagens eleitorais do parlamentar nos municípios.

Os dados foram coletados nos bancos do TSE, repositório de dados sobre eleições gerais do Brasil de 2014 (BRASIL, 2019), e a respectiva legislatura, utilizando dados das emendas apresentadas pelos referidos parlamentares nos anos de 2016, 2017 e 2018, dados disponíveis no banco Siga Brasil do Senado Federal. Por meio de estatística descritiva o estudo possibilitou expor um panorama do perfil dos deputados e suas atuações em relação à apresentação de emendas ao orçamento da União para beneficiar os estados e municípios. Utilizou-se o programa Tabwin para confecção de mapas para identificar a votação e alocação de recursos aos municípios. 


\section{Referencial Teórico}

Como explica a literatura, os estudos sobre comportamento político passaram a ser limitado por negligenciar a importância das instituições para coordenar as ações dos atores políticos. Nesse sentido, as críticas levaram a busca de considerar as regras do jogo político como campo propício ao desvelamento dos sistemas políticos, não simplesmente no plano macro, mas como arranjos que se desenham por ações orientadas por racionalidade, trajetórias históricas (path dependence) e visão de mundo (valores) das sociedades (HALL; TAYLOR, 2003).

Nesse sentido, nasce o chamado neoinstitucionalismo que ganha destaque na construção de explicações nos estudos sobre o sistema político. A questão central na abordagem neoinstitucionalista assume que as instituições políticas são resultados da interação entre atores e seu campo de atuação, constituído como jogo político. Nesse sentido, as análises da relação Executivo-Legislativo no Brasil foram fundamentadas com base em abordagens enfatizam a articulação entre desenho institucional e o campo de atuação dos políticos. Nesse sentido, os estudos sobre o funcionamento do Congresso norte-americano passaram a ser referência para desvendar de que modo o presidencialismo, como sistema de separação entre poderes, apresenta comportamentos proativos e reativos na relação Executivo-Legislativo (LIMONGI, 1994).

A utilização das ferramentas analíticas utilizadas pelos estudos legislativos para explicar o funcionamento do Congresso norte-americano, passou a ser utilizada em análises sobre a organização e funcionamento do Congresso brasileiro, porém conservando as peculiaridades das duas realidades. Enquanto o presidencialismo norte-americano funciona com predominância do bipartidarismo, há duas possibilidades para relação entre Executivo-Legislativo: governo unificado ou governo dividido ${ }^{5}$.

No presidencialismo brasileiro de multipartidarismo, a governabilidade só pode ser garantida com ampliação da base do presidente. Para tanto, qualquer perspectiva de reforma a partir das preferências do Executivo terá que ser negociada. Nesses termos, a abordagem neoinstitucionalista parte do pressuposto que as leis, regras e procedimentos fazem parte dos arranjos institucionais e organizacionais para limitar e constranger o comportamento político. Mesmo que o presidente esteja assegurado por amplos poderes constitucionais, terá que contar com aprovação do Congresso (LIMONGI, 1994).

Para explicar a interação entre regras, atores e jogo político, os estudos neoinstitucionalistas sobre o funcionamento do Congresso norte-americano, construíram três grandes vertentes: versão distributivista, informacional e partidária. Para tanto, explica diferenças significativas do comportamento parlamentar, são: o comportamento parlamentar

\footnotetext{
${ }^{5}$ O governo unificado corresponde ao modelo em que o partido do presidente é majoritário nas duas Casas Legislativas: Câmara dos representantes e Senado, já o governo dividido o partido do presidente não possui maioria em uma das Casas ou nas duas. No presidencialismo brasileiro típico de multipartidarismo, conforme essa perspectiva, o governo é sempre dividido e torna-se imprescindível a coalizão.
} 
distributivista está orientado pelos incentivos da arena eleitoral que assume o compromisso de estreitar os laços com seu distrito assegurando recursos para realização de obras que irão beneficiar os seus eleitores; por sua vez, o comportamento parlamentar informacional está orientado pelos incentivos da centralidade das comissões e seu poder decisório sobre temas especializados; já no comportamento partidário, o partido detém os mecanismos de controle do processo legislativo ao nomear lideranças para cargos estratégicos (LIMONGI, 1994).

A versão distributivista ganhou evidência nos estudos de Mayhew (1974), porque buscava explicar de que maneira os parlamentares asseguravam suas reeleições. Conforme essa versão distributivista, os deputados têm o objetivo de se reeleger e para obter êxito, buscam estreitar os laços com os seus eleitores. Isso também por considerar que no sistema eleitoral norte-americano o voto é distrital uninominal e a relação entre os deputados e os eleitores é permanente. Nesse caso, a articulação entre arena eleitoral e arena parlamentar é dada de forma direta.

Mesmo considerando outros mecanismos que expliquem a dinâmica do processo decisório, à versão distributivista interessa explicar como se dá a relação do parlamentar com o seu eleitorado. Nesse sentido, a pesquisa aqui apresentada buscou detectar de que modo essa lógica distributivista pode ser reproduzida no sistema político brasileiro. Ao tomar a definição de Ames (2003) de distrito informal considera-se que "o padrão de votação dos deputados pode assumir a seguinte tipologia: dispersa-compartilhada, dispersa-dominante, concentradacompartilhada e concentrada-dominante" (AMES, 2003, p. 65).

Para tanto, a utilização do modelo analítico de Ames (2003) para identificar um padrão de votação pela denominação de distrito informal será averiguado a partir das votações dos deputados federais da Paraíba e de Pernambuco e assim detectar a sua articulação com a apresentação e execução das emendas parlamentares ao orçamento da União.

Os fundamentos da versão distributivista consideram o comportamento parlamentar centralizado em atividades legislativas que resultem em benefícios visivelmente direcionados ao seu eleitorado ou redutos. A ideia do comportamento paroquial vem da relação que deputados estabelecem com localidades, cuja conotação é equivalente à representação clerical em sua paroquia. Esse entendimento faz também alusão aos primórdios da política norte-americana em que as lideranças distribuíam benesses aos eleitores para garantir sucesso eleitoral. Comportamento pork barril ${ }^{6}$ significa a distribuição de recursos e benefícios a indivíduos ou grupos específicos para obtenção do apoio eleitoral.

\footnotetext{
${ }^{6}$ Esse termo faz alusão à distribuição de alimentos em troca de voto, assim notabilizam-se as chamadas políticas clientelistas. Não obstante, a definição política distributivista se diferencia do clientelismo pelo tipo de bens produzidos. Enquanto no clientelismo o critério de alocação de recursos é político-partidário e os bens produzidos são privados; na política distributivista o critério de alocação de recursos é político-partidário, mas os bens produzidos são públicos, não excludentes e não rivais. Isso significa: há distinção, por exemplo, entre distribuir cestas básicas a um determinando eleitorado e alocar recursos para construção de um açude em um determinado município.
} 
Não obstante, deve-se entender tipos de políticas públicas com base nas estratégias distintas de implementação. Borges (2010) fez referência a uma tipologia associada a duas dimensões do processo de implementação de políticas públicas, são elas: critério de alocação de recursos e tipo de benefícios produzidos.

Desse modo, Borges (2010) compreende que a discussão sobre arena eleitoral, federalismo e políticas públicas pode levar a resultados distintos na realidade empírica. Para tanto, para explicar como se dá a formulação e implementação de políticas públicas em estados federais, devem-se levar em conta as razões da competição política que podem ocorrer entre os partidos e elites políticas locais e entre os estados-membros, municípios e União. Desse modo, tornam-se possíveis tipos diversos reproduzidos, conforme Quadro 1:

Quadro 1 - Análise sobre Arena Eleitoral

\begin{tabular}{|c|c|c|}
\hline \multirow{2}{*}{$\begin{array}{c}\text { Tipo de } \\
\text { benefício }\end{array}$} & \multicolumn{2}{|c|}{ Critério de alocação } \\
\cline { 2 - 3 } & Político-partidário & Universalista \\
\hline Privado & Clientelismo (I) & Focalização (III) \\
\hline Público & Distributiva (II) & Universalismo (IV) \\
\hline
\end{tabular}

Fonte: Borges (2010) p. 131.

Essa discussão de Borges (2010) ajuda a entender de que modo a competição na arena eleitoral pode direcionar as escolhas no processo decisório. No que tange ao dispositivo das emendas ao orçamento, à atribuição do parlamentar de interferir no Orçamento da União pode ser vista a partir dos dois aspectos da competição. A competição pode se dá entre os entes federativos de repartir os recursos da União para levar aos seus estados e a competição entre os líderes locais para levar recursos aos seus eleitores. Entretanto, os dois tipos podem se enquadrar em comportamento distributivista. São políticas, cujo critério de alocação é políticopartidário, mas para produzir bens públicos.

Nesse sentido, torna-se possível o comportamento de bancada através das emendas coletivas através das quais a alocação de recursos é direcionada para os estados, bem como, as emendas individuais que representam o esforço do parlamentar de levar recursos a determinados municípios, bem como também para a totalidade do estado. Assim resta saber, de que modo esse comportamento pode estar associado ao desempenho eleitoral do parlamentar conforme aqueles tipos de votação definidos por Ames (2003). As pesquisas que tratam da relação entre arena eleitoral e arena parlamentar no Brasil enfatizam os efeitos das regras eleitorais, como o sistema de lista aberta e o excessivo número de partidos, no acirramento da competição estabelecida entre os candidatos até do mesmo partido (NICOLAU, 2017; MAINWARING, 1991). 
O parlamentar que tenta a reeleição pode se encontrar numa posição vantajosa se puder contar com apoios de grupos políticos locais. Para isso, a utilização das emendas parlamentares ao orçamento tem sido estratégia recorrente no parlamento brasileiro, pois na tentativa de minimizar e até anular a concorrência em seus redutos eleitorais, os congressistas utilizam-se das emendas individuais como uma maneira de alocar recursos a determinados municípios para atender as demandas dos grupos de eleitores e garantir, desta forma, a manutenção de suas bases eleitorais, como também a conquista de novos redutos (AMES, 2003; CARVALHO, 2003).

Ames (2003) estudou o sistema eleitoral brasileiro e o padrão de competição política desenvolvido no Brasil e chegou a detectar os principais obstáculos à governabilidade no país, enfocando nas relações existentes entre as instituições políticas nacionais, principalmente as regras e práticas da política eleitoral e parlamentar e a probabilidade do Executivo adotar os recursos disponíveis para obtenção de apoio na arena legislativa para execução de ações do seu programa de governo.

Ames (2003) considera também que o Brasil vive em uma permanente crise de governabilidade, uma vez que as próprias instituições políticas criam condições que estimulam os políticos a pensarem apenas em seus ganhos pessoais e a concentrar suas propostas e recursos a um grupo determinado de eleitores ou para seus patrocinadores políticos, como se observa na versão distributivista. Além disso, o autor destaca que, embora os presidentes possuam poder de agenda, por causa dos poderes de decreto, bem como de pedir urgência para votação de projetos de sua autoria, necessita de muita habilidade para formar uma maioria parlamentar estável e sustentar seu programa de governo.

Nesse sentido, Ames (2003) considera que a fraqueza institucional do modelo do sistema eleitoral e partidário advém do próprio sistema quais sejam: 1. Há partidos importantes e eleitoralmente bem-sucedidos distribuídos por todo o espectro ideológico; 2. Os líderes dos partidos têm pouco controle sobre seus filiados, além de muitos deputados passarem boa parte do tempo em busca de nomeações e projetos de interesse específico dos seus redutos eleitorais; 3. Os partidos brasileiros dificilmente se unem para aprovar questões de interesse nacional, e como consequência o Congresso em geral não investe seriamente nos problemas econômicos e sociais mais graves; 4. Os parlamentares brasileiros têm incentivos suficientes para se ocuparem com ganhos pessoais. Assim, conclui que a preocupação com seus ganhos pessoais é resultado de variáveis institucionais as quais exercem relevância para os deputados brasileiros.

$\mathrm{O}$ autor mostra que as estratégias de campanha usadas pelos candidatos a deputado no sistema de representação proporcional de lista aberta, são adotadas no intuito de angariar votos nos municípios. Daí as emendas orçamentárias propostas pelos deputados durante sua legislatura pode se revelar como eficiente recurso para assegurar votos necessários a sua reeleição. Esta pesquisa utilizou esse modelo de análise para averiguar a articulação entre arena eleitoral e arena legislativa e a utilização do dispositivo das emendas ao orçamento da União 
pelas bancadas dos estados da Paraíba e Pernambuco no Congresso Nacional.

Embora exista uma gama de estudos sobre essa articulação entre arena eleitoral e arena parlamentar essa forma de explicar o comportamento dos parlamentares tem gerado debate e discordância entre autores da ciência política brasileira. Outra forma de interpretar essa articulação vem de outra interpretação sobre os incentivos para cooperação na arena parlamentar em detrimento do comportamento individualista da arena eleitoral. Essa interpretação ganha centralidade com os trabalhos de Figueiredo; Limongi (1996; 1999; 2002). Segundo esses autores, os trabalhos legislativos são organizados com base na lógica partidária, de modo que, políticas distributivistas têm campo limitado. Não obstante, os dispositivos das emendas parlamentares são considerados a janela de oportunidade para os parlamentares entrarem em negociação com o poder Executivo para viabilizar as demandas de seus aliados e eleitores.

A apresentação e a possível execução das emendas fazem parte das estratégias para firmar apoios eleitorais e manter suas bases em eleições subsequentes. Pereira; Mueller (2002; 2003) consideram que a principal importância das emendas individuais ao orçamento deve-se aos seus efeitos em votações futuras. Assim demonstraram que as execuções das emendas tiveram feitos positivos na reeleição do parlamentar.

Carvalho (2003) discute essa temática da articulação entre arena eleitoral e arena parlamentar fazendo algumas ponderações. No que tange aos dispositivos das emendas testa hipóteses com base no modelo distributivista e chega à conclusão que os constituences de formação variada fornecerão estruturas de incentivos diversos para os congressistas, os quais irão, como decorrência, privilegiar objetivos diferenciados na arena legislativa (CARVALHO, 2003, p. 24).

A distribuição espacial ou geografia do voto pode ser sumarizada da seguinte forma: a) embora Executivo esteja assegurado por fortes poderes constitucionais e com possibilidade de articulação no colégio de líderes e se constitua uma estrutura interna centralizada do Legislativo, esse desenho institucional não é suficiente para criar uma barreira da conexão arena parlamentar e arena eleitoral; b) no Brasil há diversos de incentivos advindos da arena eleitoral. Desse modo há multiplicidade de desenho da conexão eleitoral no país, isto é, há realidades que indicam em direção ao paroquialismo em outras em direção ao universalismo legislativo; c) a distribuição espacial do voto exerce fortes incentivos para definição de estratégias dos legisladores para assegurar a reeleição, mostra a natureza do grau de competitividade do mercado político em que atuam e; d) o modelo distributivista para a situação do Brasil tem limitações, devido a diversidade de conexão eleitoral aqui existente, dessa forma, não se pode explicar o comportamento legislativo brasileiro somente pela perspectiva distributivista nem tampouco somente pelo monopólio partidário. 
A partir dos estudos feitos acerca do tema, esta pesquisa ora apresentada não teve como objetivo entender os motivos da reeleição dos parlamentares, mas averiguar em que medida os deputados federais da Paraíba e Pernambuco vêm fazendo uso dos dispositivos constitucionais para alocação de recursos para os municípios através das emendas orçamentárias individuais e como esse comportamento pode ser associado aos resultados eleitorais para mesma legislatura. Para isso, a seguir, apresenta-se análise descritiva dos dados obtidos.

\section{Metodologia}

A pesquisa faz uma análise descritiva sobre a relação entre votação dos deputados federais nos municípios e apresentação/execução de emendas parlamentares ao orçamento da União. Para tanto, foram realizados trabalhos de investigação em fontes secundárias e possibilitaram desenhar o comportamento parlamentar dos deputados dos estados da Paraíba e Pernambuco com relação à utilização e destino dos recursos obtidos através de emendas orçamentárias individuais.

As fontes de pesquisa sobre resultados eleitorais foram os bancos de dados do repositório do TSE e Siga Brasil Portal do Orçamento do Senado Federal, cujas informações dizem respeito às características dos candidatos e suas votações em todos os municípios paraibanos e pernambucanos e informações sobre todas as emendas apresentadas por cada parlamentar durante a legislatura analisada. Para tratamento dos dados fez-se uso de estatística descritiva e elaboração de mapas dos estados com a identificação da votação de cada deputado federal em cada município e o direcionamento dos recursos através das emendas.

Os mapas foram confeccionados pelo uso do software Tabiwn e permitem identificar o percentual da votação do deputado em cada município, utilizando variação da votação através de cores, que variam entre municípios que aparecem sem coloração, indicando zero voto, a municípios que aparecem com variação na intensidade da coloração, indicando forma crescente no percentual de votação. A identificação da alocação de recursos deu-se por meio de círculos que variam de tamanho na forma crescente conforme a quantidade de emendas.

A pesquisa faz uso do método comparado (LANDMAN, 2003) utilizando poucos casos para identificar semelhanças e diferenças entre a distribuição espacial do voto e a distribuição das emendas parlamentares individuais ao orçamento da União. A análise permitiu fazer comparações entre as performances dos deputados do mesmo estado, bem como entre os estados analisados. A delimitação do campo empírico está sumarizada na Tabela 1 e demostra dados estratificados por quantidade de municípios por tamanho do eleitorado e índice de Desenvolvimento Humano Municipal (IDHM). 
Tabela 1 - Número de Municípios por faixa de eleitores 2019 - Paraíba e Pernambuco

\begin{tabular}{c|c|c|c|c|c|c|c|c|c|c}
\hline & $\begin{array}{c}\text { IDHM } \\
\text { Médio }\end{array}$ & $\begin{array}{c}\text { Municípios } \\
\mathbf{P B}\end{array}$ & $\boldsymbol{\%}$ & $\begin{array}{c}\text { Eleitores } \\
\mathbf{P B}\end{array}$ & $\boldsymbol{\%}$ & $\begin{array}{l}\text { IDHM } \\
\text { Médio }\end{array}$ & $\begin{array}{c}\text { Municípios } \\
\mathbf{P E}\end{array}$ & $\boldsymbol{\%}$ & $\begin{array}{c}\text { Eleitores } \\
\mathbf{P E}\end{array}$ & $\%$ \\
\hline $\begin{array}{c}\text { Até 10 mil } \\
\text { eleitores }\end{array}$ & 0,581 & 157 & 70,4 & 784.489 & 27,8 & 0,583 & 37 & 20 & 287.221 & 4,33 \\
\hline $\begin{array}{c}\text { De 10.001 } \\
\text { a 60 mil } \\
\text { eleitores }\end{array}$ & 0,604 & 61 & 27,8 & 1.081 .329 & 37,3 & 0,590 & 132 & 73 & 3.004 .228 & 45,3 \\
\hline $\begin{array}{c}\text { De 60.001 } \\
\text { acima de } \\
\text { eleitores }\end{array}$ & 0,692 & 5 & 2,24 & 1.030 .630 & 35,6 & 0,680 & 16 & 8,64 & 3.342 .535 & 50,4 \\
\hline Total & 0,625 & 223 & 100 & 2.896 .448 & 100 & $\mathbf{0 , 6 1 7}$ & 185 & 100 & 6.633 .984 & 100 \\
\hline
\end{tabular}

Fonte: Elaborado pelo autor, 2020, a partir de dados (BRASIL, 2019) e Atlas do Desenvolvimento Humano no Brasil-PNUD.

\section{Resultados e Discussão}

\subsection{Desempenho eleitoral e apresentação e emendas orçamentárias de deputados federais da Paraíba e Pernambuco}

Antes de delinear o quadro do legislativo federal dos estados da Paraíba e de Pernambuco são apresentados dados relativos às principais características de cada parlamentar. Em relação aos deputados federais eleitos em 2014, mostrados nas tabelas 2 e 3, as coligações foram responsáveis pela maioria vitoriosa. Isso demonstra que no sistema multipartidário brasileiro, em eleições de representação proporcional, as coligações são caminho mais seguro para obtenção de êxito eleitoral. Todavia, podem ter efeitos danosos para o significado da representação política (NICOLAU, 2017).

Sobre os dados referentes ao estado da Paraíba, Tabela 2, somente os eleitos do partido PMDB apresentaram candidaturas isoladas. As coligações que tiveram o PSB e PSDB, siglas de peso na representação estadual, constituíram alianças compostas de 11 e 14 partidos, respectivamente, lograram êxito, conquistando número significativo de deputados federais. Esse é dado que explica a estratégia das coligações para pequenos partidos que não atingem o quociente eleitoral. 
Tabela 2 - Deputados Federais eleitos em 2014 na Paraíba

\begin{tabular}{|c|c|c|c|}
\hline Depu & Partido & Eleito por* & Coligação \\
\hline $\begin{array}{l}\text { Aguinaldo Veloso } \\
\text { Borges Ribeiro }\end{array}$ & $\begin{array}{c}\text { Partido } \\
\text { Progressista }\end{array}$ & $\begin{array}{l}\text { Eleito por } \\
\text { QP }\end{array}$ & $\begin{array}{l}\text { PSB / DEM / PRTB / PDT / PRP / } \\
\text { PV / PT / PSL / PC do B / PHS / PPL }\end{array}$ \\
\hline $\begin{array}{l}\text { Benjamim Gomes } \\
\text { Maranhão Neto }\end{array}$ & Solidariedade & $\begin{array}{l}\text { Eleito por } \\
\text { Média }\end{array}$ & $\begin{array}{c}\mathrm{PSDB} / \mathrm{PEN} / \mathrm{PR} \text { / PTB / PSD / SD / } \\
\mathrm{PMN} / \mathrm{PPS} \text { / PT do B / PTN / PRB / } \\
\mathrm{PSDC} / \mathrm{PSC} / \mathrm{PP}\end{array}$ \\
\hline $\begin{array}{c}\text { Damião Feliciano } \\
\text { da Silva }\end{array}$ & $\begin{array}{c}\text { Partido } \\
\text { Democrático } \\
\text { Trabalhista }\end{array}$ & $\begin{array}{l}\text { Eleito por } \\
\text { média }\end{array}$ & $\begin{array}{c}\mathrm{PSB} / \mathrm{DEM} \text { / PRTB / PDT / PRP / } \\
\mathrm{PV} / \mathrm{PT} / \mathrm{PSL} \text { / PC do B / PHS / PPL }\end{array}$ \\
\hline $\begin{array}{l}\text { Efraim de Araújo } \\
\text { Morais Filho }\end{array}$ & Democratas & $\begin{array}{l}\text { Eleito por } \\
\text { QP }\end{array}$ & $\begin{array}{c}\text { PSB / DEM / PRTB / PDT / PRP / } \\
\text { PV / PT / PSL / PC do B / PHS / PPL }\end{array}$ \\
\hline $\begin{array}{c}\text { Hugo Mota } \\
\text { Wanderley da } \\
\text { Nóbrega }\end{array}$ & $\begin{array}{c}\text { Partido do } \\
\text { Movimento } \\
\text { Democrático } \\
\text { Brasileiro }\end{array}$ & $\begin{array}{l}\text { Eleito por } \\
\text { QP }\end{array}$ & PMDB \\
\hline $\begin{array}{l}\text { Luiz Albuquerque } \\
\text { Couto }\end{array}$ & $\begin{array}{c}\text { Partido Dos } \\
\text { Trabalhadores }\end{array}$ & $\begin{array}{l}\text { Eleito por } \\
\text { QP }\end{array}$ & $\begin{array}{c}\text { PSB / DEM / PRTB / PDT / PRP / } \\
\text { PV / PT / PSL / PC do B / PHS / PPL }\end{array}$ \\
\hline $\begin{array}{l}\text { Manoel Alves da } \\
\text { Silva Júnior }\end{array}$ & $\begin{array}{c}\text { Partido do } \\
\text { Movimento } \\
\text { Democrático } \\
\text { Brasileiro }\end{array}$ & $\begin{array}{l}\text { Eleito por } \\
\text { média }\end{array}$ & PMDB \\
\hline $\begin{array}{l}\text { Pedro Oliveira } \\
\text { Cunha Lima }\end{array}$ & $\begin{array}{l}\text { Partido da } \\
\text { Social } \\
\text { Democracia } \\
\text { Brasileira }\end{array}$ & $\begin{array}{l}\text { Eleito por } \\
\text { QP }\end{array}$ & $\begin{array}{c}\mathrm{PSDB} \text { / PEN / PR / PTB / PSD / SD / } \\
\mathrm{PMN} \mathrm{/} \mathrm{PPS} \mathrm{/} \mathrm{PT} \mathrm{do} \mathrm{B} \mathrm{/} \mathrm{PTN} \mathrm{/} \mathrm{PRB} \mathrm{/} \\
\text { PSDC / PSC / PP }\end{array}$ \\
\hline $\begin{array}{l}\text { Rômulo José de } \\
\text { Gouveia }\end{array}$ & $\begin{array}{l}\text { Partido Social } \\
\text { Democrático }\end{array}$ & $\begin{array}{l}\text { Eleito por } \\
\text { QP }\end{array}$ & $\begin{array}{c}\mathrm{PSDB} / \mathrm{PEN} / \mathrm{PR} \text { / PTB / PSD / SD / } \\
\mathrm{PMN} \mathrm{/} \mathrm{PPS} \mathrm{/} \mathrm{PT} \mathrm{do} \mathrm{B} \mathrm{/} \mathrm{PTN} \mathrm{/} \mathrm{PRB} \mathrm{/} \\
\mathrm{PSDC} / \mathrm{PSC} / \mathrm{PP}\end{array}$ \\
\hline $\begin{array}{l}\text { Veneziano Vital do } \\
\text { Rego segundo Neto }\end{array}$ & $\begin{array}{c}\text { Partido do } \\
\text { Movimento } \\
\text { Democrático } \\
\text { Brasileiro }\end{array}$ & $\begin{array}{l}\text { Eleito por } \\
\qquad \text { QP }\end{array}$ & PMDB \\
\hline $\begin{array}{l}\text { José Wellington } \\
\text { Roberto }\end{array}$ & $\begin{array}{l}\text { Partido da } \\
\text { República }\end{array}$ & $\begin{array}{l}\text { Eleito por } \\
\text { QP }\end{array}$ & $\begin{array}{c}\mathrm{PSDB} / \mathrm{PEN} \text { / PR / PTB / PSD / SD / } \\
\mathrm{PMN} \mathrm{/} \mathrm{PPS} \mathrm{/} \mathrm{PT} \mathrm{do} \mathrm{B} \mathrm{/} \mathrm{PTN} \mathrm{/} \mathrm{PRB} \mathrm{/} \\
\text { PSDC / PSC / PP }\end{array}$ \\
\hline
\end{tabular}




\begin{tabular}{c|c|c|c|c} 
José Wilson & Partido & Eleito por & PSDB / PEN / PR / PTB / PSD / SD / \\
Santiago Filho & Trabalhista & QP & PMN / PPS / PT do B / PTN / PRB / \\
& Brasileiro & QP & PSDC / PSC / PP
\end{tabular}

Fonte: Tribunal Superior Eleitoral, 2019.

* Assumem as seguintes nomenclaturas: $\mathrm{QP}=$ Quociente Partidário; EM= Eleito por média; EL= Eleito pela votação nominal; $\mathrm{SP}=$ Suplente que está assumindo o mandato na atual legislatura.

A Tabela 2 mostrou como as coligações tornaram-se artifício vulgar no anseio de maximizar o voto dos candidatos sem a preocupação com afinidades de agenda a partir de espectro ideológico. Essa configuração de coligações em candidaturas por regras proporcionais passou a ser vista como ponto fulcral para dar significado às dificuldades da representação (NICOLAU, 2017). Nesse caso, o desenho de multipartidarismo excessivo passou a ser visto como problemático e factível a mudanças. Nesses termos as críticas produziram efeito desejado, a proibição de coligações em eleições para a Câmara dos deputados e demais casas legislativas dos estados e municípios veio a calhar.

Sobre o estado de Pernambuco, Tabela 3, nenhum partido apresentou candidatura isolada, sendo a maioria dos deputados eleitos, 18 dos 25 pela coligação encabeçada pelo PSB, ficando de fora apenas 7 deputados de outras coligações. Isso significa que a coligação com forte presença do PSB justifica-se pelo comando de sua expressiva liderança o Ex-Governador Eduardo Campos, nas eleições de 2014, pois alcança uma bancada significativa, chegando a ocupar $72 \%$ do total das cadeiras do estado no Congresso.

Tabela 3 - Deputados Federais eleitos em 2014 em Pernambuco

\begin{tabular}{|c|c|c|c|}
\hline Deputado & Partido & Eleito por * & Coligação \\
\hline $\begin{array}{c}\text { Adalberto Cavalcanti } \\
\text { Rodrigues }\end{array}$ & $\begin{array}{c}\text { Partido } \\
\text { Trabalhista } \\
\text { Brasileiro }\end{array}$ & Eleito por QP & $\begin{array}{c}\mathrm{PTB} / \mathrm{PT} / \mathrm{PSC} / \mathrm{PDT} / \mathrm{PRB} \\
\text { / PT do B }\end{array}$ \\
\hline $\begin{array}{c}\text { André Carlos Alves de } \\
\text { Paula Filho }\end{array}$ & $\begin{array}{l}\text { Partido Social } \\
\text { Democrático }\end{array}$ & Eleito por QP & $\begin{array}{l}\mathrm{PSB} / \mathrm{PMDB} \text { / PC do B / PV } \\
\text { / PR / PSD / PPS / PSDB / } \\
\mathrm{SD} / \mathrm{PPL} / \mathrm{DEM} / \mathrm{PROS} / \\
\text { PP / PEN / PTC }\end{array}$ \\
\hline $\begin{array}{c}\text { Anderson Ferreira } \\
\text { Rodrigues }\end{array}$ & PR & Eleito por QP & $\begin{array}{l}\mathrm{PSB} / \mathrm{PMDB} / \mathrm{PC} \text { do B / PV } \\
\text { / PR / PSD / PPS / PSDB / } \\
\mathrm{SD} / \mathrm{PPL} / \mathrm{DEM} / \mathrm{PROS} / \\
\text { PP / PEN / PTC }\end{array}$ \\
\hline $\begin{array}{c}\text { Heberte Lamark } \\
\text { Gomes da Silva }\end{array}$ & $\begin{array}{l}\text { Partido da } \\
\text { Social }\end{array}$ & Eleito por QP & $\begin{array}{l}\mathrm{PSB} / \mathrm{PMDB} / \mathrm{PC} \text { do B / PV } \\
\text { / PR / PSD / PPS / PSDB / }\end{array}$ \\
\hline
\end{tabular}




\begin{tabular}{|c|c|c|c|}
\hline & $\begin{array}{c}\text { Democracia } \\
\text { Brasileira }\end{array}$ & & $\begin{array}{l}\text { SD / PPL / DEM / PROS / } \\
\text { PP / PEN / PTC }\end{array}$ \\
\hline $\begin{array}{c}\text { Bruno Cavalcanti de } \\
\text { Araújo }\end{array}$ & $\begin{array}{l}\text { Partido da } \\
\text { Social } \\
\text { Democracia } \\
\text { Brasileira }\end{array}$ & Eleito por QP & $\begin{array}{c}\mathrm{PSB} / \mathrm{PMDB} \text { / PC do B / PV } \\
\text { / PR / PSD / PPS / PSDB / } \\
\mathrm{SD} / \mathrm{PPL} / \mathrm{DEM} / \mathrm{PROS} / \\
\mathrm{PP} / \mathrm{PEN} / \mathrm{PTC}\end{array}$ \\
\hline Daniel Pires Coelho & $\begin{array}{l}\text { Partido da } \\
\text { Social } \\
\text { Democracia } \\
\text { Brasileira }\end{array}$ & & $\begin{array}{c}\mathrm{PSB} / \mathrm{PMDB} \text { / PC do B / PV } \\
\text { / PR / PSD / PPS / PSDB / } \\
\mathrm{SD} / \mathrm{PPL} / \mathrm{DEM} / \mathrm{PROS} / \\
\text { PP / PEN / PTC }\end{array}$ \\
\hline $\begin{array}{c}\text { Danilo Jorge de Barros } \\
\text { Cabral }\end{array}$ & $\begin{array}{l}\text { Partido } \\
\text { Socialista } \\
\text { Brasileiro }\end{array}$ & Eleito por QP & $\begin{array}{l}\mathrm{PSB} / \mathrm{PMDB} \text { / PC do B / PV } \\
\text { / PR / PSD / PPS / PSDB / } \\
\mathrm{SD} / \mathrm{PPL} / \mathrm{DEM} / \mathrm{PROS} / \\
\mathrm{PP} / \mathrm{PEN} / \mathrm{PTC}\end{array}$ \\
\hline $\begin{array}{c}\text { Eduardo Henrique da } \\
\text { Fonte de Albuquerque } \\
\text { Silva }\end{array}$ & $\begin{array}{c}\text { Partido } \\
\text { Progressista }\end{array}$ & Eleito por QP & $\begin{array}{l}\text { PSB / PMDB / PC do B / PV } \\
\text { / PR / PSD / PPS / PSDB / } \\
\text { SD / PPL / DEM / PROS / } \\
\text { PP / PEN / PTC }\end{array}$ \\
\hline Fernando Coelho Filho & $\begin{array}{c}\text { Partido } \\
\text { Socialista } \\
\text { Brasileiro }\end{array}$ & Eleito por QP & $\begin{array}{l}\mathrm{PSB} / \mathrm{PMDB} \text { / PC do B / PV } \\
\text { / PR / PSD / PPS / PSDB / } \\
\mathrm{SD} / \mathrm{PPL} / \mathrm{DEM} / \mathrm{PROS} / \\
\mathrm{PP} / \mathrm{PEN} / \mathrm{PTC}\end{array}$ \\
\hline $\begin{array}{c}\text { Felipe Augusto Lyra } \\
\text { Carreras }\end{array}$ & $\begin{array}{l}\text { Partido } \\
\text { Socialista } \\
\text { Brasileiro }\end{array}$ & Eleito por QP & $\begin{array}{c}\mathrm{PSB} / \mathrm{PMDB} \text { / PC do B / PV } \\
\text { / PR / PSD / PPS / PSDB / } \\
\mathrm{SD} / \mathrm{PPL} / \mathrm{DEM} / \mathrm{PROS} / \\
\text { PP / PEN / PTC }\end{array}$ \\
\hline Luiz Gonzaga Patriota & $\begin{array}{l}\text { Partido } \\
\text { Socialista } \\
\text { Brasileiro }\end{array}$ & Eleito por QP & $\begin{array}{l}\mathrm{PSB} / \mathrm{PMDB} \text { / PC do B / PV } \\
\text { / PR / PSD / PPS / PSDB / } \\
\mathrm{SD} / \mathrm{PPL} / \mathrm{DEM} / \mathrm{PROS} / \\
\mathrm{PP} / \mathrm{PEN} / \mathrm{PTC}\end{array}$ \\
\hline $\begin{array}{l}\text { Jarbas de Andrade } \\
\text { Vasconcelos }\end{array}$ & $\begin{array}{l}\text { Partido do } \\
\text { Movimento } \\
\text { Democrático } \\
\text { Brasileiro }\end{array}$ & Eleito por QP & $\begin{array}{l}\mathrm{PSB} / \mathrm{PMDB} \text { / PC do B / PV } \\
\text { / PR / PSD / PPS / PSDB / } \\
\mathrm{SD} / \mathrm{PPL} / \mathrm{DEM} / \mathrm{PROS} / \\
\text { PP / PEN / PTC }\end{array}$ \\
\hline $\begin{array}{c}\text { João Fernando Pontual } \\
\text { Coutinho }\end{array}$ & $\begin{array}{c}\text { Partido } \\
\text { Socialista }\end{array}$ & Eleito por QP & $\begin{array}{l}\mathrm{PSB} / \mathrm{PMDB} \text { / PC do B / PV } \\
\text { / PR / PSD / PPS / PSDB / }\end{array}$ \\
\hline
\end{tabular}




\begin{tabular}{|c|c|c|c|}
\hline & Brasileiro & & $\begin{array}{c}\text { SD / PPL / DEM / PROS / } \\
\text { PP / PEN / PTC }\end{array}$ \\
\hline $\begin{array}{c}\text { Jorge Wicks Côrte } \\
\text { Real }\end{array}$ & $\begin{array}{l}\text { Partido } \\
\text { Trabalhista } \\
\text { Brasileiro }\end{array}$ & Eleito por QP & $\begin{array}{c}\mathrm{PTB} / \mathrm{PT} / \mathrm{PSC} / \mathrm{PDT} / \mathrm{PRB} \\
\text { / PT do B }\end{array}$ \\
\hline $\begin{array}{c}\text { Kaio César de Moura } \\
\text { Maniçoba Ferraz }\end{array}$ & $\begin{array}{l}\text { Partido } \\
\text { Humanista da } \\
\text { Solidariedade }\end{array}$ & Eleito por QP & $\begin{array}{c}\text { PSDC / PTN / PRP / PSL / } \\
\text { PHS / PRTB }\end{array}$ \\
\hline $\begin{array}{l}\text { Luciana Barbosa de } \\
\text { Oliveira Santos }\end{array}$ & PC do B & $\begin{array}{l}\text { Eleita por } \\
\text { Média }\end{array}$ & $\begin{array}{l}\mathrm{PSB} / \mathrm{PMDB} \text { / PC do B / PV } \\
\text { / PR / PSD / PPS / PSDB / } \\
\mathrm{SD} / \mathrm{PPL} / \mathrm{DEM} \mathrm{/} \mathrm{PROS} \mathrm{/} \\
\text { PP / PEN / PTC }\end{array}$ \\
\hline $\begin{array}{c}\text { Marinaldo Rosendo de } \\
\text { Albuquerque }\end{array}$ & $\begin{array}{c}\text { Partido } \\
\text { Socialista } \\
\text { Brasileiro }\end{array}$ & Eleito por QP & $\begin{array}{l}\mathrm{PSB} / \mathrm{PMDB} / \mathrm{PC} \text { do B / PV } \\
\text { / PR / PSD / PPS / PSDB / } \\
\mathrm{SD} / \mathrm{PPL} / \mathrm{DEM} / \mathrm{PROS} \text { / } \\
\text { PP / PEN / PTC }\end{array}$ \\
\hline $\begin{array}{c}\text { José Mendonça } \\
\text { Bezerra Filho }\end{array}$ & Democratas & $\begin{array}{l}\text { Eleito por } \\
\text { Média }\end{array}$ & $\begin{array}{l}\mathrm{PSB} / \mathrm{PMDB} \text { / PC do B / PV } \\
\text { / PR / PSD / PPS / PSDB / } \\
\mathrm{SD} / \mathrm{PPL} / \mathrm{DEM} \mathrm{/} \mathrm{PROS} \mathrm{/} \\
\text { PP / PEN / PTC }\end{array}$ \\
\hline $\begin{array}{l}\text { Francisco Eurico da } \\
\text { Silva }\end{array}$ & $\begin{array}{l}\text { Partido } \\
\text { Socialista } \\
\text { Brasileiro }\end{array}$ & Eleito por QP & $\begin{array}{l}\mathrm{PSB} / \mathrm{PMDB} / \mathrm{PC} \text { do B / PV } \\
\text { / PR / PSD / PPS / PSDB / } \\
\mathrm{SD} / \mathrm{PPL} / \mathrm{DEM} / \mathrm{PROS} \text { / } \\
\text { PP / PEN / PTC }\end{array}$ \\
\hline $\begin{array}{c}\text { Ricardo Teobaldo } \\
\text { Cavalcanti }\end{array}$ & $\begin{array}{l}\text { Partido } \\
\text { Trabalhista } \\
\text { Brasileiro }\end{array}$ & Eleito por QP & $\begin{array}{c}\mathrm{PTB} / \mathrm{PT} / \mathrm{PSC} / \mathrm{PDT} / \mathrm{PRB} \\
\text { / PT do B }\end{array}$ \\
\hline $\begin{array}{l}\text { Sebastião Ignácio de } \\
\text { Oliveira Júnior }\end{array}$ & $\begin{array}{l}\text { Partido da } \\
\text { República }\end{array}$ & Eleito por QP & $\begin{array}{l}\mathrm{PSB} / \mathrm{PMDB} \text { / PC do B / PV } \\
\text { / PR / PSD / PPS / PSDB / } \\
\mathrm{SD} / \mathrm{PPL} / \mathrm{DEM} \mathrm{/} \mathrm{PROS} \mathrm{/} \\
\text { PP / PEN / PTC }\end{array}$ \\
\hline Silvio Serafim Costa & $\begin{array}{l}\text { Partido Social } \\
\text { Cristão }\end{array}$ & Eleito por QP & $\begin{array}{c}\mathrm{PTB} / \mathrm{PT} / \mathrm{PSC} / \mathrm{PDT} / \mathrm{PRB} \\
\text { / PT do B }\end{array}$ \\
\hline $\begin{array}{c}\text { Francisco Tadeu } \\
\text { Barbosa de Alencar }\end{array}$ & $\begin{array}{l}\text { Partido } \\
\text { Socialista } \\
\text { Brasileiro }\end{array}$ & Eleito por QP & $\begin{array}{l}\mathrm{PSB} / \mathrm{PMDB} \text { / PC do B / PV } \\
\text { / PR / PSD / PPS / PSDB / } \\
\mathrm{SD} / \mathrm{PPL} / \mathrm{DEM} / \mathrm{PROS} /\end{array}$ \\
\hline
\end{tabular}




\begin{tabular}{|c|c|c|c|}
\hline \multirow{2}{*}{$\begin{array}{c}\text { Wolney Queiroz } \\
\text { Maciel }\end{array}$} & Partido & & PP / PEN / PTC \\
\hline & $\begin{array}{c}\text { Democrático } \\
\text { Trabalhista }\end{array}$ & Eleito por QP & $\begin{array}{c}\text { PTB / PT / PSC / PDT / PRB } \\
\text { / PT do B }\end{array}$ \\
\hline \multirow{2}{*}{ Zeca Cavalcante } & Partido & & \\
& Trabalhista & Eleito por QP & PTB / PT / PSC / PDT / PRB \\
& Brasileiro & & / PT do B \\
\hline
\end{tabular}

Fonte: Tribunal Superior Eleitoral, 2019.

* Assumem as seguintes nomenclaturas: $\mathrm{QP}=$ Quociente Partidário; $\mathrm{EM}=$ Eleito por Média; EL = Eleito pela votação nominal; $\mathrm{SP}=$ Suplente que está assumindo o mandato na atual legislatura.

As Tabelas 4 e 5 abaixo demonstram panorama sobre o número de legislaturas por número de deputados federais nos dois estados analisados. Essa demonstração permite visualizar como a reeleição dos deputados paraibanos nas eleições de 2014 aparece com mais visibilidade. Já a bancada pernambucana tem taxa de renovação significativa se aproximando da metade.

Tabela 4 - Quantidade de Legislaturas dos deputados da Paraíba

\begin{tabular}{|c|c|c|} 
Número de Legislaturas & $\begin{array}{c}\text { Número de Deputados } \\
\text { Federais }\end{array}$ & $\%$ \\
\hline $\mathbf{1}$ & 2 & $16,6 \%$ \\
\hline $\mathbf{2}$ & 4 & $33,33 \%$ \\
\hline $\mathbf{3}$ & 3 & $25 \%$ \\
\hline $\mathbf{4}$ & 2 & $16,6 \%$ \\
\hline
\end{tabular}

Fonte: Tribunal Superior Eleitoral, 2019.

As Tabelas 4 e 5 representam a quantidade de legislaturas por deputado. Nota-se que há uma variedade de deputados com mais de uma legislatura. Os dados revelam que há diferença entre os dois estados, no que toca a inovação da bancada. Enquanto a bancada da Paraíba apresentou aproximadamente $17 \%$ na taxa de novatos na Câmara dos Deputados, a bancada de Pernambuco apresentou uma taxa de $44 \%$. 
Tabela 5 - Quantidade de legislaturas dos deputados de Pernambuco

Número de Legislaturas Número de Deputados \%

Federais

\begin{tabular}{|c|c|c|}
\hline $\mathbf{1}$ & 11 & $44 \%$ \\
\hline $\mathbf{2}$ & 5 & $20 \%$ \\
\hline $\mathbf{3}$ & 6 & $24 \%$ \\
\hline $\mathbf{7}$ & 2 & $8 \%$ \\
\hline
\end{tabular}

Fonte: Tribunal Superior Eleitoral, 2019.

Por sua vez, há uma variedade de candidatos que buscam a reeleição no Poder Legislativo Federal, estado da Paraíba 58\% dos deputados federais eleitos representam aqueles que ocupam entre a segunda e terceira legislaturas. Enquanto que a taxa de parlamentares mais experientes, sendo representantes em 4 legislaturas, chega também a aproximadamente a $17 \%$. Já em relação aos dados de Pernambuco, a trajetória da experiência legislativa varia, isto é, aqueles deputados que ocupavam entre a segunda e terceira legislaturas representam também $44 \%$ da bancada.

Desse modo, pode-se dizer que a maioria da bancada paraibana já ocupava cadeiras em legislaturas anteriores, variando entre 2 a 5 legislaturas. Já em relação à bancada pernambucana, como a taxa de novatos representou percentual considerável de $44 \%$, isto é, dos 25 deputados eleitos em 2014, 11 ocuparam pela primeira vez uma cadeira na Câmara dos Deputados, então, $56 \%$ dos deputados pernambucanos já exerciam experiência legislativa variando entre 2 a 7 legislaturas.

\subsection{Emendas individuais dos deputados paraibanos e pernambucanos}

O poder de alterar o orçamento da União é uma das mudanças significativas que a Constituição de 1988 trouxe para resgatar o lugar estratégico do Poder Legislativo na alocação de recursos aos demais entes da federação, sejam eles, estados ou municípios. Nesse sentido, a pesquisa buscou visualizar como esse dispositivo tem sido utilizado pelas bancadas estaduais da Paraíba e Pernambuco para viabilizar os interesses dos seus eleitores.

Nesse sentido, pôde-se detectar a intensidade no uso desse dispositivo pelos parlamentares das bancadas paraibanas e pernambucanas e sua distribuição espacial. Do mesmo modo permitiu averiguar como essas emendas podem ser articuladas com a votação dos deputados nos municípios e em todo o estado.

As Tabelas 6 e 7 apresentam as quantidades de emendas individuais ao orçamento de cada deputado federal nos dois estados analisados, nelas pode-se observar que o dispositivo das emendas é amplamente utilizado pelas duas bancadas dos dois estados. Entretanto, há oscilações 
entre apresentação e execução, isso significa dizer que a apresentação nem sempre resulta em alocação de recursos para os entes federativos ${ }^{7}$.

Tabela 6 - Total de emendas apresentadas e executadas por deputado/ano Paraíba ${ }^{8}$

\begin{tabular}{|c|c|c|c|c|c|c|c|c|}
\hline \multirow{2}{*}{$\begin{array}{l}\text { Nome do } \\
\text { deputado }\end{array}$} & \multicolumn{3}{|c|}{$\begin{array}{l}\text { Total de emendas } \\
\text { apresentadas }\end{array}$} & \multirow[t]{2}{*}{$\begin{array}{c}\text { Total } \\
\text { Trienal }\end{array}$} & \multicolumn{3}{|c|}{$\begin{array}{l}\text { Total de emendas } \\
\text { executadas }\end{array}$} & \multirow[t]{2}{*}{$\begin{array}{c}\text { Total } \\
\text { Trienal }\end{array}$} \\
\hline & 2016 & 2017 & 2018 & & 2016 & 2017 & 2018 & \\
\hline $\begin{array}{l}\text { Aguinaldo } \\
\text { Ribeiro }\end{array}$ & 10 & 7 & 11 & 28 & 7 & 7 & 11 & 25 \\
\hline $\begin{array}{l}\text { Benjamim } \\
\text { Maranhão }\end{array}$ & 15 & 10 & 12 & 37 & 13 & 10 & 12 & 35 \\
\hline Damião Feliciano & 25 & 7 & 20 & 52 & 16 & 7 & 20 & 43 \\
\hline Efraim Filho & 21 & 12 & 18 & 61 & 20 & 12 & 18 & 50 \\
\hline Hugo Mota & 12 & 5 & 10 & 27 & 6 & 5 & 10 & 21 \\
\hline Luiz Couto & 18 & 12 & 22 & 52 & 15 & 11 & 22 & 48 \\
\hline Manoel Júnior & 9 & 16 & 0 & 25 & 9 & 16 & 0 & 25 \\
\hline $\begin{array}{l}\text { Pedro Cunha } \\
\text { Lima }\end{array}$ & 24 & 9 & 21 & 54 & 20 & 9 & 21 & 50 \\
\hline Rômulo Gouveia & 21 & 8 & 13 & 42 & 19 & 8 & 13 & 40 \\
\hline Veneziano Vital & 18 & 0 & 20 & 38 & 14 & 0 & 20 & 34 \\
\hline $\begin{array}{l}\text { Wellington } \\
\text { Roberto }\end{array}$ & 20 & 16 & 15 & 51 & 10 & 15 & 15 & 40 \\
\hline Wilson Filho & 17 & 8 & 15 & 40 & 12 & 8 & 15 & 35 \\
\hline Total & & & & 507 & & & & 446 \\
\hline
\end{tabular}

A Tabela 6 demonstra a franca utilização das emendas por parte de todos os parlamentares da Paraíba em todo o triênio da legislatura. Do total de emendas individualmente por todos os parlamentares resultou em 507 apresentadas e 446 executadas, número significativo. Isto é, na operação de subtração entre apresentação e execução em termos relativos atinge o patamar de $12 \%$, enquanto $88 \%$ do total de emendas de todos os parlamentares alocaram recursos em estado e municípios. Isso demonstra ser instrumento valioso para eleitos estreitarem laços com eleitores. Já a Tabela 7 referente à viabilidade das emendas pelos deputados federais pernambucanos, os dados revelam semelhanças, 898 apresentadas, 767 foram executadas, atingindo a marca de $85 \%$.

\footnotetext{
${ }^{7}$ O Orçamento impositivo representa hoje uma conquista do Poder Legislativo que conseguiu mecanismo para obrigar o Executivo a executar as emendas apresentadas pelos parlamentares.

${ }^{8}$ Vale salientar que o Poder Executivo apresenta o planejamento do Orçamento anual em um ano que precede a sua execução. Nesse sentido, os parlamentares eleitos em 2014, apresentaram e votaram a proposta orçamentaria dos anos 2016, 2017 e 2018.
} 
Tabela 7 - Total de emendas apresentadas e executadas por deputado/ano Pernambuco

\begin{tabular}{|c|c|c|c|c|c|c|c|c|}
\hline \multirow[t]{2}{*}{ Nome do deputado } & \multicolumn{3}{|c|}{$\begin{array}{l}\text { Total de emendas } \\
\text { apresentadas }\end{array}$} & \multirow{2}{*}{$\begin{array}{c}\text { Total } \\
\text { Trienal }\end{array}$} & \multicolumn{3}{|c|}{$\begin{array}{l}\text { Total de emendas } \\
\text { executadas }\end{array}$} & \multirow{2}{*}{$\begin{array}{c}\text { Total } \\
\text { Trienal }\end{array}$} \\
\hline & 2016 & 2017 & 2018 & & 2016 & 2017 & 2018 & \\
\hline Adalberto Cavalcanti & 15 & 7 & 16 & 38 & 14 & 7 & 16 & 37 \\
\hline André de Paula & 0 & 11 & 17 & 28 & 0 & 8 & 16 & 24 \\
\hline Anderson Ferreira & 9 & 7 & 0 & 16 & 9 & 6 & 0 & 15 \\
\hline Betinho Gomes & 19 & 4 & 15 & 38 & 11 & 3 & 10 & 24 \\
\hline Bruno Araújo & 15 & 3 & 4 & 22 & 14 & 3 & 4 & 21 \\
\hline Daniel Coelho & 10 & 6 & 12 & 28 & 9 & 4 & 11 & 24 \\
\hline Danilo Cabral & 0 & 12 & 13 & 25 & 0 & 8 & 13 & 21 \\
\hline Eduardo da Fonte & 12 & 20 & 15 & 47 & 11 & 13 & 13 & 37 \\
\hline $\begin{array}{c}\text { Fernando Coelho } \\
\text { Filho }\end{array}$ & 10 & 6 & 11 & 27 & 8 & 6 & 11 & 25 \\
\hline Felipe Carreras & 0 & 0 & 16 & 16 & 0 & 0 & 15 & 15 \\
\hline Gonzaga Patriota & 23 & 23 & 20 & 66 & 17 & 21 & 19 & 57 \\
\hline Jarbas Vasconcelos & 8 & 9 & 16 & 33 & 7 & 6 & 15 & 28 \\
\hline $\begin{array}{l}\text { João Fernando } \\
\text { Coutinho }\end{array}$ & 18 & 12 & 12 & 42 & 13 & 8 & 12 & 33 \\
\hline Jorge Côrte Real & 23 & 25 & 24 & 72 & 20 & 14 & 23 & 57 \\
\hline Kaio Maniçoba & 14 & 14 & 11 & 39 & 13 & 12 & 11 & 36 \\
\hline Luciana Santos & 25 & 23 & 22 & 70 & 17 & 17 & 20 & 54 \\
\hline Marinaldo Rosendo & 12 & 17 & 12 & 41 & 11 & 14 & 11 & 36 \\
\hline Mendonça Filho & 6 & 0 & 8 & 14 & 6 & 0 & 8 & 14 \\
\hline Pastor Eurico & 5 & 11 & 10 & 26 & 5 & 11 & 9 & 25 \\
\hline Ricardo Teobaldo & 8 & 8 & 11 & 27 & 7 & 7 & 11 & 25 \\
\hline Sebastião Oliveira & 0 & 0 & 0 & $\mathbf{0}$ & 0 & 0 & 0 & $\mathbf{0}$ \\
\hline Silvio Costa & 25 & 20 & 24 & 69 & 24 & 16 & 24 & 64 \\
\hline Tadeu Alencar & 21 & 19 & 13 & 53 & 20 & 14 & 13 & 47 \\
\hline Wolney Queiroz & 12 & 9 & 8 & 29 & 5 & 9 & 7 & 21 \\
\hline Zeca Cavalcanti & 13 & 12 & 7 & 32 & 10 & 10 & 7 & 27 \\
\hline Total & & & & 898 & & & & 767 \\
\hline
\end{tabular}

Fonte: Siga Brasil - BRASIL, 2019.

No entanto, os dados indicam que essa diferença não tem padrão, há ano que as emendas de cada parlamentar são mais executadas e anos que são menos executadas, isso para os dois campos empíricos da análise.

Os dados das Tabelas 8 e 9 apontam a quantidade de emendas executadas pelo Executivo que foram apresentadas individualmente por cada deputado em cada ano. Nas duas bancadas as emendas individuais foram amplamente utilizadas. 
Tabela 8 - Quantidade de emendas orçamentárias executadas por deputado/ano Paraíba

\begin{tabular}{|c|c|c|c|c|c|c|c|}
\hline \multirow[t]{2}{*}{ Deputado } & \multirow[t]{2}{*}{ Partido } & \multicolumn{3}{|c|}{ Ano } & \multirow[t]{2}{*}{ Total } & \multirow[t]{2}{*}{ Média } & \multirow[t]{2}{*}{ Desvio } \\
\hline & & 2016 & 2017 & 2018 & & & \\
\hline $\begin{array}{c}\text { Aguinaldo } \\
\text { Ribeiro }\end{array}$ & PP & 07 & 07 & 11 & 25 & 8,33 & 1,78 \\
\hline $\begin{array}{l}\text { Benjamim } \\
\text { Maranhão }\end{array}$ & PSB & 13 & 10 & 12 & 35 & 11,67 & 1,11 \\
\hline Dr. Damião & PDT & 16 & 07 & 20 & 43 & 14,33 & 4,89 \\
\hline Efraim Filho & Democratas & 20 & 12 & 18 & 50 & 16,67 & 3,11 \\
\hline Hugo Mota & PMDB & 06 & 05 & 10 & 21 & 7 & 2,00 \\
\hline Luiz Couto & PT & 15 & 11 & 22 & 48 & 16 & 4,00 \\
\hline $\begin{array}{l}\text { Manoel } \\
\text { Júnior }\end{array}$ & PMDB & 09 & 16 & 00 & 25 & 8,33 & 5,56 \\
\hline $\begin{array}{c}\text { Pedro Cunha } \\
\text { Lima }\end{array}$ & PSDB & 20 & 09 & 21 & 50 & 16,67 & 5,11 \\
\hline $\begin{array}{l}\text { Rômulo } \\
\text { Gouveia }\end{array}$ & PSD & 19 & 08 & 13 & 40 & 13,33 & 3,78 \\
\hline $\begin{array}{c}\text { Veneziano } \\
\text { Vital }\end{array}$ & PMDB & 14 & 00 & 20 & 34 & 11,33 & 7,56 \\
\hline $\begin{array}{c}\text { Wellington } \\
\text { Roberto }\end{array}$ & PR & 10 & 15 & 15 & 40 & 13,33 & 2,22 \\
\hline Wilson Filho & PTB & 12 & 08 & 15 & 35 & 11,67 & 2,44 \\
\hline
\end{tabular}

Fonte: Siga Brasil - BRASIL, 2019.

Não obstante, levando em conta os três anos, registrados nas Tabelas 8 e 9, há variação da média das emendas de cada parlamentar que foram executadas. Na totalidade dos três anos de legislatura na bancada da Paraíba a média das emendas dos deputados varia entre 7 a 17 aproximadamente. Já a variação da média na bancada de Pernambuco assume os valores entre 5 a 19. 
Tabela 9 - Quantidade de emendas orçamentárias executadas por deputado/ano Pernambuco

\begin{tabular}{|c|c|c|c|c|c|c|c|}
\hline \multirow{2}{*}{ Deputado } & \multirow{2}{*}{ Partido } & & \multirow{2}{*}{ Total } & \multirow{2}{*}{ Média } & \multirow{2}{*}{ Desvio } \\
\hline & & 2016 & 2017 & 2018 & & & \\
\hline $\begin{array}{l}\text { Adalberto } \\
\text { Cavalcanti }\end{array}$ & PTB & 14 & 07 & 16 & 37 & 12,33 & 3,56 \\
\hline André de Paula & PSD & 00 & 08 & 16 & 24 & 8 & 5,33 \\
\hline $\begin{array}{l}\text { Anderson } \\
\text { Ferreira }\end{array}$ & PR & 09 & 06 & 00 & 15 & 5 & 3,33 \\
\hline Betinho Gomes & PSDB & 11 & 03 & 10 & 24 & 8 & 3,33 \\
\hline Bruno Araújo & PSDB & 14 & 03 & 04 & 21 & 7 & 4,67 \\
\hline Daniel Coelho & PSDB & 09 & 04 & 11 & 24 & 8 & 2,67 \\
\hline Danilo Cabral & PSB & 00 & 08 & 13 & 21 & 7 & 4,67 \\
\hline $\begin{array}{l}\text { Eduardo da } \\
\text { Fonte }\end{array}$ & PP & 11 & 13 & 13 & 37 & 11,67 & 0,89 \\
\hline $\begin{array}{c}\text { Fernando } \\
\text { Coelho Filho }\end{array}$ & PSB & 08 & 06 & 11 & 25 & 8,33 & 1,78 \\
\hline Felipe Carreras & PSB & 00 & 00 & 15 & 15 & 5 & 6,67 \\
\hline $\begin{array}{l}\text { Gonzaga } \\
\text { Patriota }\end{array}$ & PSB & 17 & 21 & 19 & 57 & 19 & 1,33 \\
\hline $\begin{array}{c}\text { Jarbas } \\
\text { Vasconcelos }\end{array}$ & PMDB & 07 & 06 & 15 & 28 & 9,33 & 3,78 \\
\hline $\begin{array}{c}\text { João Fernando } \\
\text { Coutinho }\end{array}$ & PSB & 13 & 08 & 12 & 33 & 11 & 2,00 \\
\hline $\begin{array}{c}\text { Jorge Côrtes } \\
\text { Real }\end{array}$ & PTB & 20 & 14 & 23 & 57 & 19 & 3,33 \\
\hline Kaio Maniçoba & PHS & 13 & 12 & 11 & 36 & 12 & 0,67 \\
\hline Luciana Santos & PC do B & 17 & 17 & 20 & 54 & 18 & 1,33 \\
\hline $\begin{array}{c}\text { Marinaldo } \\
\text { Rosendo }\end{array}$ & PSB & 11 & 14 & 11 & 36 & 12 & 1,33 \\
\hline Mendonça Filho & DEM & 06 & 00 & 08 & 14 & 4,67 & 3,11 \\
\hline Pastor Eurico & PSB & 05 & 11 & 09 & 25 & 8,33 & 2,22 \\
\hline $\begin{array}{l}\text { Ricardo } \\
\text { Teobaldo }\end{array}$ & PTB & 07 & 07 & 11 & 25 & 8,33 & 1,78 \\
\hline $\begin{array}{c}\text { Sebastião } \\
\text { Oliveira }\end{array}$ & PR & 00 & 00 & 00 & 0 & 0 & 0,00 \\
\hline Silvio Costa & PSC & 24 & 16 & 24 & 64 & 21,33 & 3,56 \\
\hline
\end{tabular}




\begin{tabular}{|c|c|c|c|c|c|c|c|}
\hline Tadeu Alencar & PSB & 20 & 14 & 13 & 47 & 15,67 & 2,89 \\
\hline Wolney Queiroz & PDT & 05 & 09 & 07 & 21 & 7 & 1,33 \\
\hline Zeca Cavalcante & PTB & 10 & 10 & 07 & 27 & 9 & 1,33 \\
\hline
\end{tabular}

Fonte: Siga Brasil - BRASIL, 2019.

O Gráfico 1 apresenta diferença percentual na destinação das emendas orçamentárias individuais dos deputados federais paraibanos. Os dados chamam atenção para diferença significativa entre emendas destinadas a municípios e estados nos dois campos empíricos analisados.

Os resultados da Paraíba indicam que há preponderância de emendas destinadas ao ente federativo estadual, isto significa que, no Gráfico 1, 63\% das emendas individuais dos parlamentares paraibanos tiveram como destino o estado, sem especificação a entes municipais, enquanto $37 \%$ foram destinadas diretamente para determinados municípios.

Gráfico 1 - Diferença percentual entre emendas para municípios e estado da Paraíba

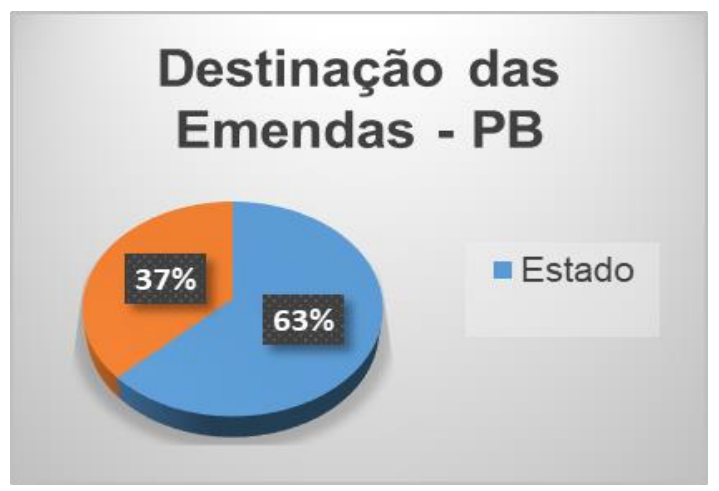

Fonte: Tribunal Superior Eleitoral, 2019.

Os resultados de Pernambuco seguem a mesma lógica, Gráfico 2, indica que 68\% das emendas orçamentárias individuais foram direcionadas para o ente estadual e 32\% para determinados municípios. Esses achados são significativos para reflexão sobre a influência dos parlamentares paraibanos e pernambucanos em municípios com base nas emendas orçamentárias. Os dados sugerem que a perspectiva de conexão entre arena eleitoral e arena parlamentar para os dois campos empíricos analisados com base apenas nas emendas parlamentares não se verifica. Na próxima sessão apresentam-se mapas para sobrepor a faixa percentual da votação de cada deputado em cada município e a alocação das emendas. 
Gráfico 2 - Diferença percentual entre emendas para municípios e estado de Pernambuco

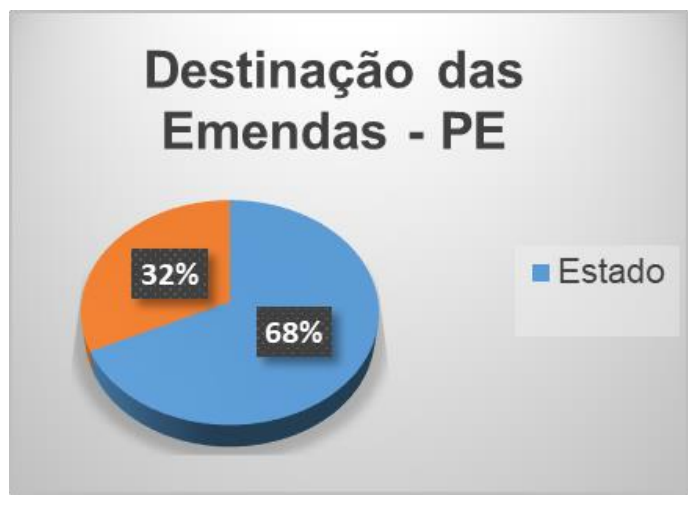

Fonte: Tribunal Superior Eleitoral, 2019.

Nesse sentido, torna-se possível visualizar melhor a conexão eleitoral e o dispositivo das emendas individuais dos deputados federais paraibanos e pernambucanos. A partir dos gráficos acima foi possível levantar outras questões sobre o comportamento distributivista no Congresso. O paroquialismo dos deputados dos dois estados a partir das emendas não está majoritariamente relacionado ao ente federal municipal, mas estadual.

A disposição para alocação de emendas diretamente aos municípios tem menor evidência. Esses dados podem estar relacionados ao tipo de votação de cada deputado, que na tipologia de Ames (2003), pode assumir o tipo disperso-compartilhado. Esse tipo de votação corresponde ao resultado eleitoral de candidatos que tiveram votação estendida em toda circunscrição estadual e compartilharam votos com outros concorrentes. Esses casos implicam arena eleitoral bastante competitiva.

\subsection{Distribuição espacial do voto e alocação de recursos nos municípios}

Nesta sessão buscou-se apresentar como a votação individual de cada deputado em cada município pode ser visualizada por faixa percentual de votos e como as emendas destinadas aos municípios podem ser identificadas. Foram elaborados mapas da Paraíba e Pernambuco para cada deputado através dos quais se podem verificar a existência de padrões de votação e de alocação de emendas para os municípios.

Vale salientar que embora o estado da Paraíba seja menor em termos territoriais e populacionais, possui mais municípios que o estado de Pernambuco, 223 e 185 respectivamente. A Paraíba, portanto, possui uma quantidade maior de pequenos municípios. Isso pode explicar a diferença entre tipo de votação dos deputados federais, dispersa ou concentrada, uma vez que pequenos municípios representam menor magnitude eleitoral, o candidato para ser eleito necessita abarcar maior extensão territorial, havendo assim, maior propensão à dispersão da votação. 
Embora a pesquisa tenha elaborado mapas para todos os deputados, apresentam-se somente alguns exemplos para os dois estados. A escolha dos deputados se deu pela quantidade de emendas, pela diferença na distribuição do voto e pelo protagonismo do parlamentar nas duas arenas legislativa e eleitoral. As regiões coloridas dos mapas correspondem aos municípios onde o deputado teve votação, assim, quanto mais escura a região maior votação. Já as regiões brancas correspondem aos municípios onde não houve votação. As emendas são identificadas por circunferência de cor laranja, quanto maior o círculo, maior a quantidade de emendas àquele município.

Os mapas 1, 2, 3, 4, e 5, apresentam dados sobre a distribuição espacial do voto e alocação de emendas por parlamentares no estado da Paraíba. No mapa 1, referente à articulação entre votação do deputado Aguinaldo Ribeiro (PP) e suas emendas, pode-se dizer que há tendência ao tipo de votação dispersa-compartilhada, mas contendo regiões brancas no mapa que apresentam zero votação em alguns municípios. Em relação à destinação das emendas, o referido deputado não alocou emendas para municípios onde teve maior percentual de votação, correspondente a regiões mais escuras do mapa. Alocando assim emendas até para município onde não teve votação.

Mapa 1 - Paraíba - Distribuição espacial do voto e alocação de emendas do deputado Aguinaldo Ribeiro

(PP)

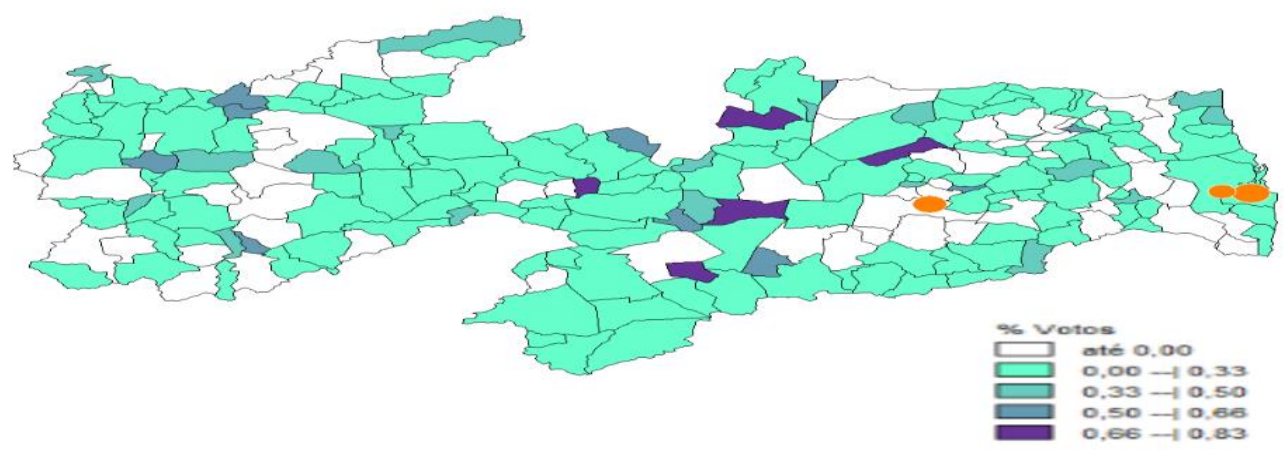

Fonte: Elaboração própria, 2019, a partir de dados (BRASIL, 2019).

No mapa 02, referente à articulação entre votação do deputado Pedro Cunha Lima (PSDB), há distinção tanto no tipo de votação bem como na alocação das emendas. O deputado tem votação dispersa-compartilhada em quase todo o território paraibano e alocou emendas também de forma dispersa para municípios de maior votação, concentrando uma quantidade maior de emendas para uma determinada região, como município de Campina Grande e no seu entorno. 
Mapa 2 - Paraíba - Distribuição espacial do voto e alocação de emendas do deputado Pedro Cunha Lima (PSDB)

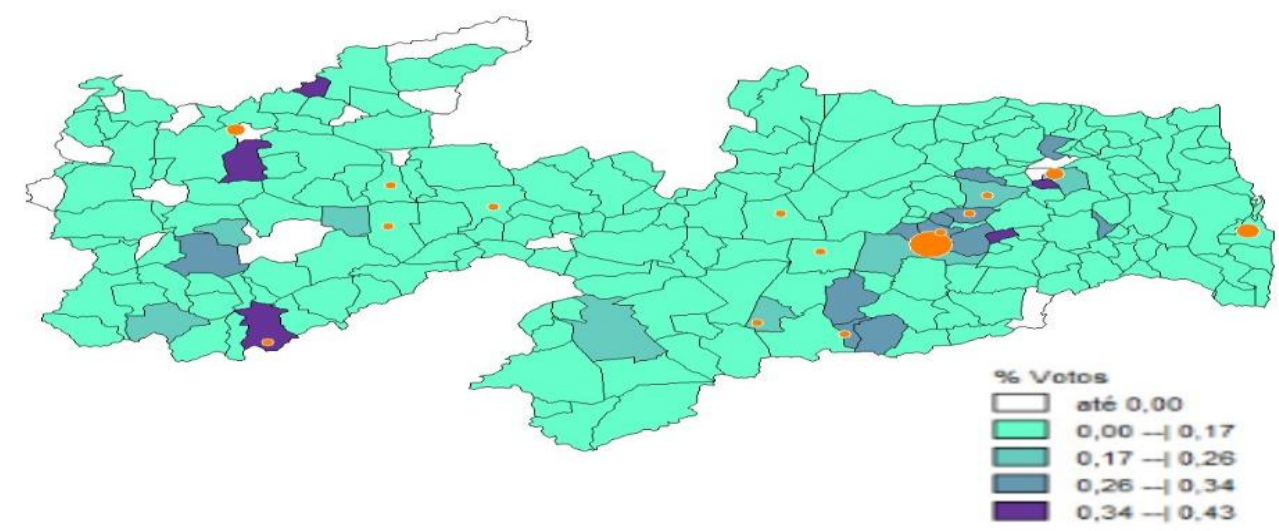

Fonte: Elaboração própria, 2019, a partir de dados (BRASIL, 2019).

No mapa 03, referente à articulação entre votação do deputado Benjamin Maranhão (PSB), a distribuição da votação difere dos dois mapas anteriores, há uma parte do mapa de municípios contíguos onde o deputado apresenta maior distribuição.

No entanto, não corresponde às regiões mais escuras e muitos municípios onde o deputado teve zero voto. Em relação à alocação das emendas há município onde Benjamin Maranhão teve maior percentual de votos e não alocou emendas. Entretanto alocou para a capital onde representa maior colégio eleitoral e que também teve votação. Esse tipo de alocação para o maior município do estado foi também a tendência do deputado Aguinaldo Ribeiro e diferente da alocação do deputado Pedro Cunha Lima que teve uma votação mais dispersa, mas também destinou emendas para região metropolitana, sem dúvida, pela importância da magnitude eleitoral.

Mapa 3- Paraíba - Distribuição espacial do voto e alocação de emendas do deputado Benjamin Maranhão (PSB)

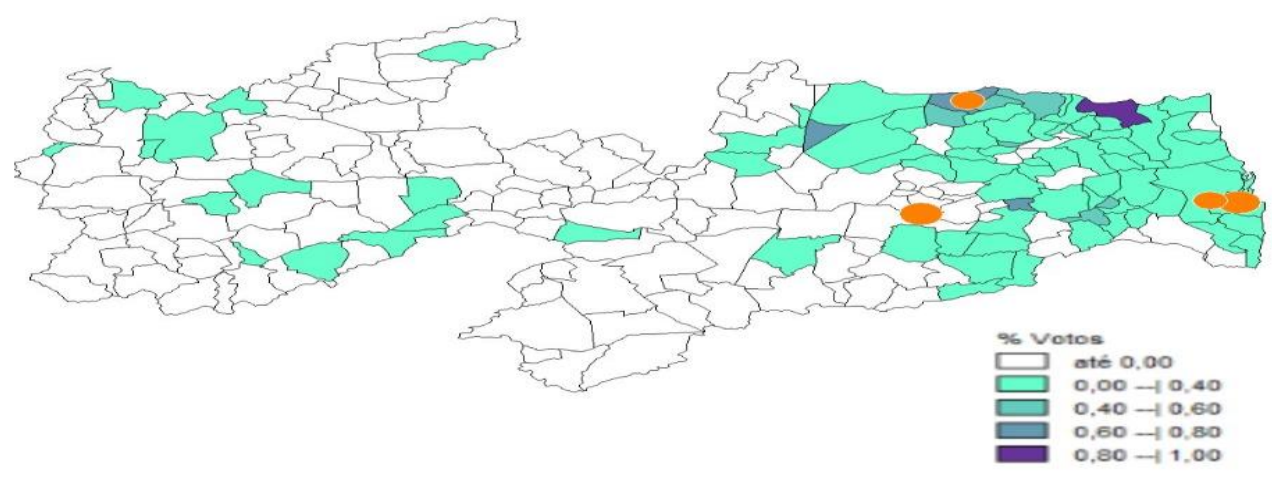

Fonte: Elaboração própria ,2019, a partir de dados (BRASIL, 2019). 
Nos mapas 4 e 5, relativos à articulação entre votação dos deputados Efraim Filho (DEM) e Luiz Couto (PT) e as emendas, apresentam muitas semelhanças e algumas diferenças. Os deputados apresentaram votação dispersa-compartilhada, mas a votação de Luiz Couto (PT) apresentou maior abrangência, com poucas regiões brancas no mapa.

No tocante à distribuição das emendas, também há semelhanças, os deputados alocaram para municípios onde apresentaram votações, direcionando grande parte para região metropolitana, representada pelo tamanho da circunferência de cor laranja na região centro leste do mapa.

Mapa 4 - Paraíba - Distribuição espacial do voto e alocação de emendas do deputado Efraim Filho

(DEM)

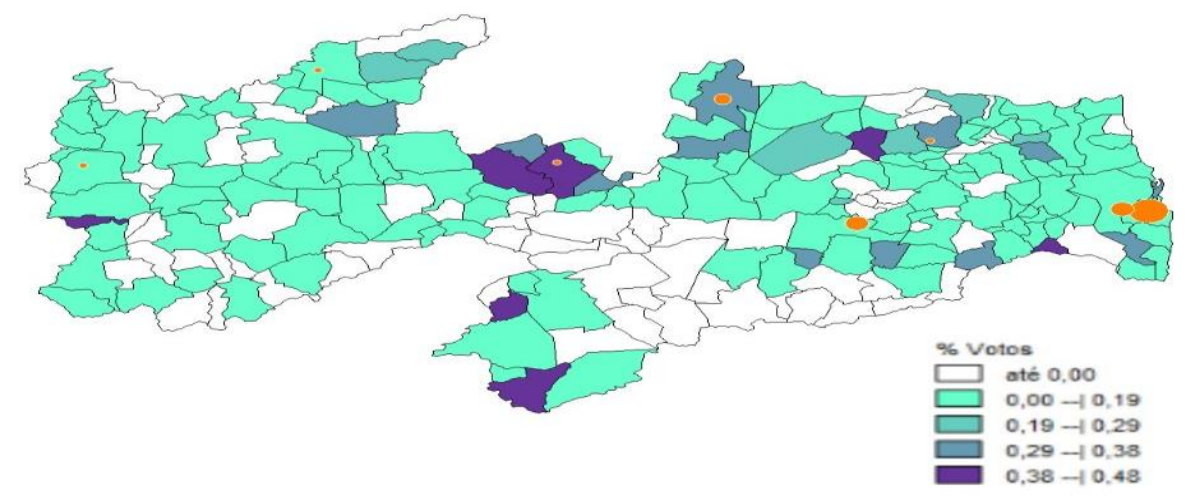

Fonte: Elaboração própria, 2019, a partir de dados (BRASIL, 2019).

Mapa 5 - Paraíba - Distribuição espacial do voto e alocação de emendas do deputado Luiz Couto (PT)

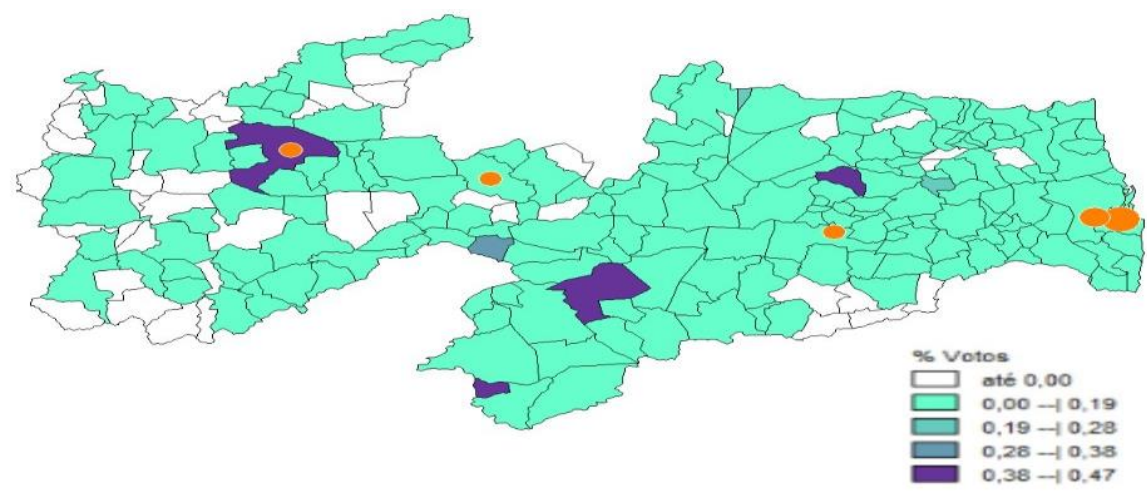

Fonte: Elaboração própria, 2019, a partir de dados (BRASIL, 2019).

Esses cinco mapas apresentados, sobre o estado da Paraíba, demonstram distintos tipos de distribuição espacial do voto, bem como distintos tipos de alocação de recursos para os municípios paraibanos. Os mapas 6 e 7 , referentes à articulação entre votação dos deputados e emendas no estado de Pernambuco, permitem observar realidades distintas entre a performance do deputado Fernando Coelho (PSB) e Jarbas Vasconcelos (PMDB). 
Pode-se perceber que no primeiro caso, há tipo de votação mais concentrada em algumas regiões distantes e concentração de emendas para a região sudoeste de maior votação, especificamente, para município de Petrolina, base eleitoral do deputado. Já no segundo caso a votação do deputado possui maior dispersão, mas com regiões de zero votação.

Nesse caso, há distinção também na alocação das emendas, o deputado Jarbas Vasconcelos, distribuiu maior parte das emendas para região metropolitana, onde começou sua trajetória política e teve votação compartilhada, mas também não alocou para regiões onde obteve maior percentual de votação, alocando até emendas para região de zero votação.

Mapa 6 - Pernambuco - Distribuição espacial do voto e alocação de emendas do deputado Fernando Coelho (PSB)

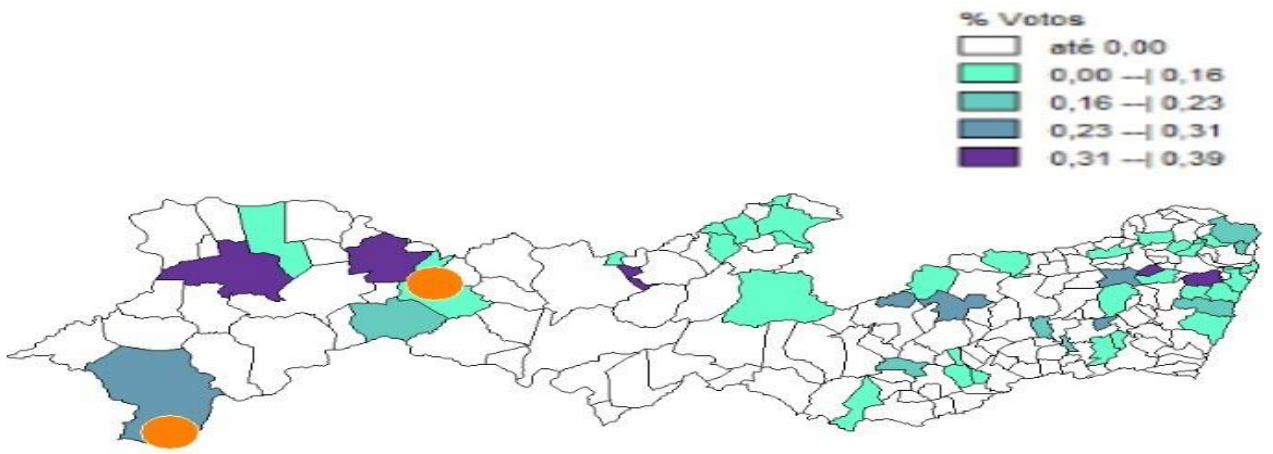

Fonte: Elaboração própria, 2019, a partir de dados (BRASIL, 2019).

Vale salientar que Pernambuco por apresentar magnitude eleitoral e municípios maiores, as estratégias dos candidatos, em relação à Paraíba, são diferentes porque permitem o candidato buscar votos regiões específicas.

Mapa 7 - Pernambuco - Distribuição espacial do voto e alocação de emendas do deputado Jarbas Vasconcelos (PMDB)

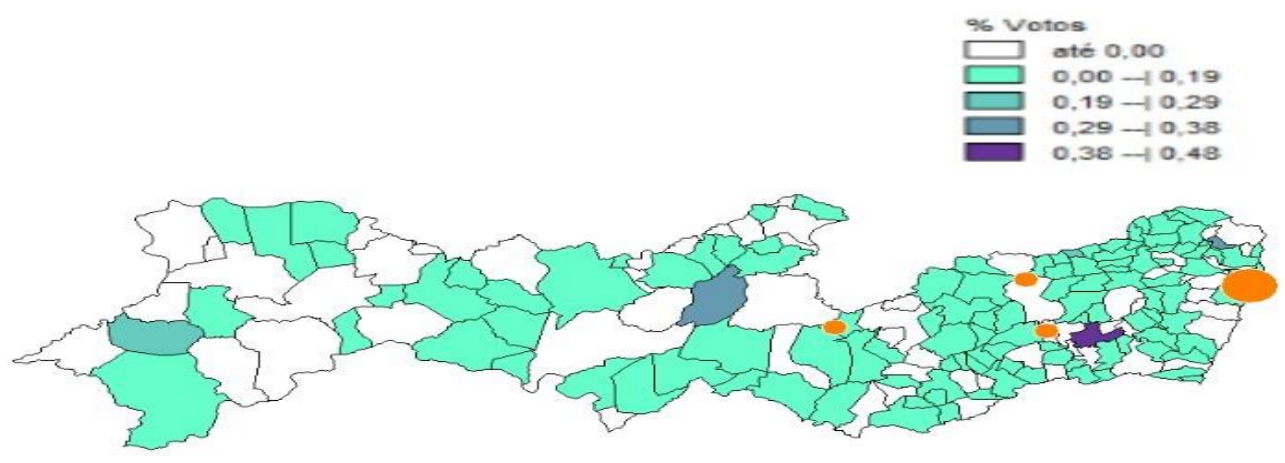

Fonte: Elaboração própria, 2019, a partir de dados (BRASIL, 2019). 
Nesse sentido, os mapas demonstram que a votação dos deputados pernambucanos estaria mais próxima da denominação de distritos informais, mas mesmo assim, ainda apresenta fraqueza como evidência empírica predominante. Há casos em que os deputados mesmo recebendo votação em determinadas regiões não destina emendas, e, em contrapartida a alocação para regiões onde não apresentou votação. Nos mapas 8,9 e 10, sobre o estado de Pernambuco, é possível visualizar esse fenômeno.

Mapa 8 - Pernambuco - Distribuição espacial do voto e alocação de emendas do deputado Silvio Costa (PSC)

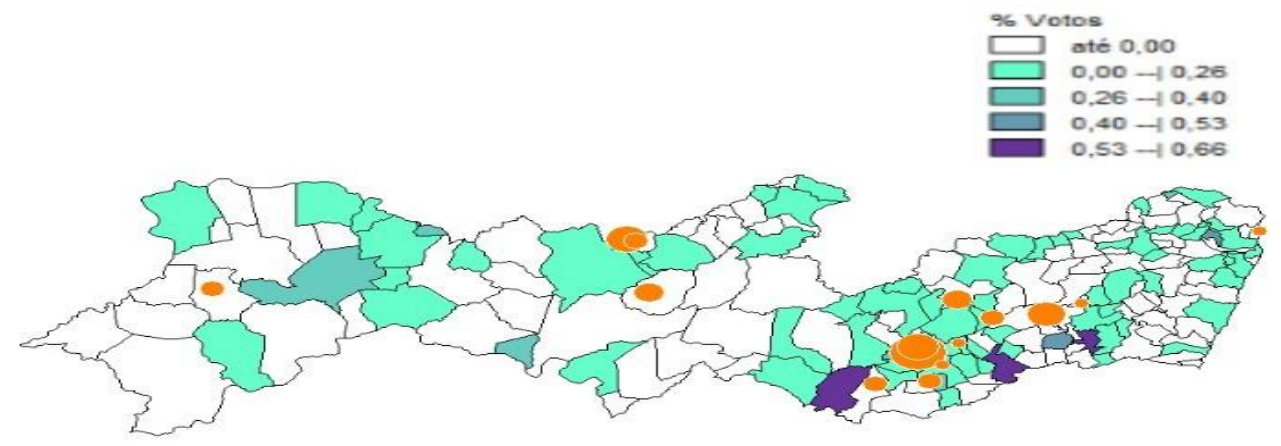

Fonte: Elaboração própria, 2019, a partir de dados (BRASIL, 2019).

Mapa 9 - Pernambuco - Distribuição espacial do voto e alocação de emendas da deputada Luciana Santos (PCdoB)

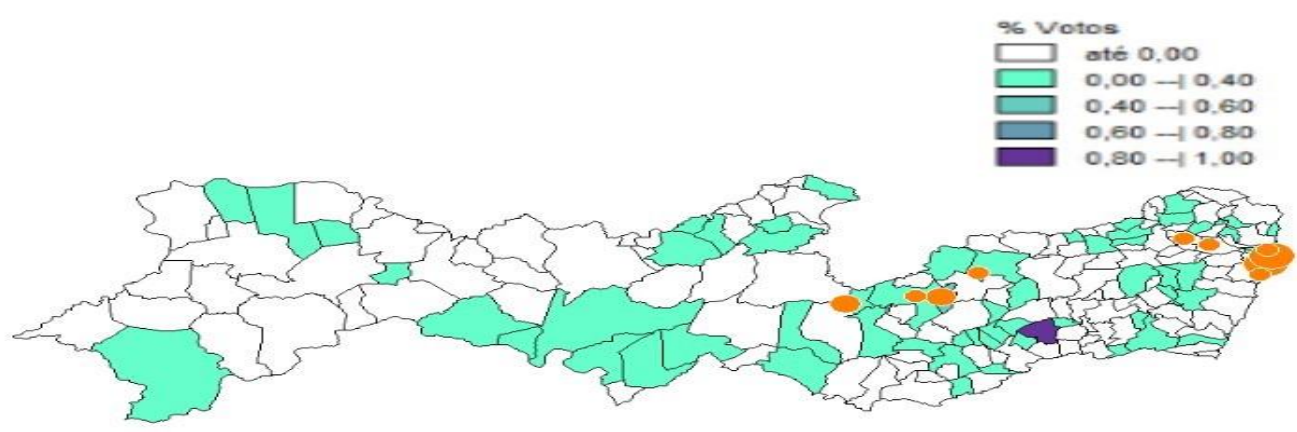

Fonte: Elaboração própria, 2019, a partir de dados (BRASIL, 2019). 
Mapa 10 - Pernambuco - Distribuição espacial do voto e alocação de emendas do deputado Luiz

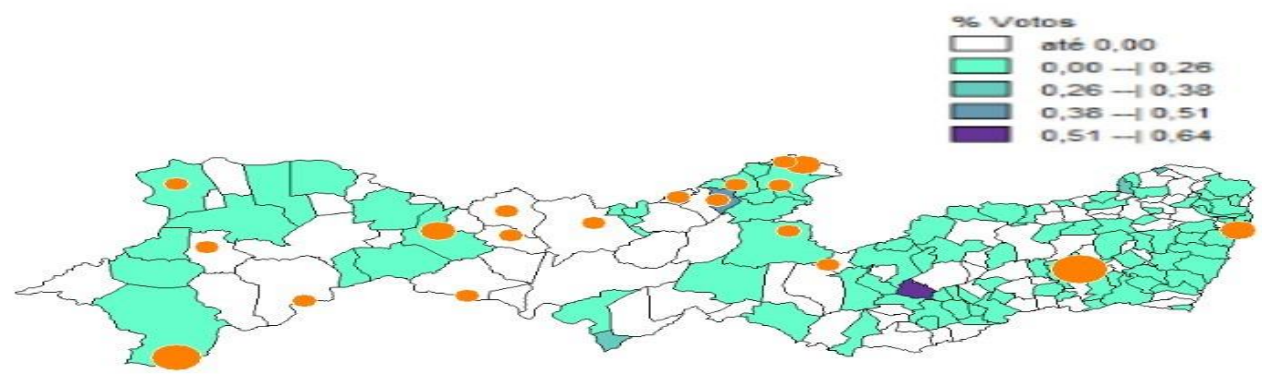

Fonte: Elaboração própria, 2019, a partir de dados (BRASIL, 2019).

Tais dados evidenciam o processo dinâmico de distribuição do voto e de direcionamento de emendas no estado de Pernambuco, o que favorece a visualização de posicionamentos dos parlamentares e direcionamento de recursos, abarcando, dessa maneira, cenários de análises mais amplos, no tocante à alocação de recursos nesses espaços.

\section{Conclusão}

A discussão sobre a relação entre distribuição espacial do voto e alocação de recursos aos entres da federação ainda é bastante controversa e ainda carece de verificação empírica. A pesquisa aqui apresentada buscou responder algumas lacunas. No entanto, os resultados aqui apresentados ainda são bastante diminutos para assumir qualquer pretensão de generalização do fenômeno e de invalidação do significado dos distritos informais.

A partir de então é possível algumas reflexões como guisa de conclusões e como orientação para agendas de pesquisas futuras. É possível dizer que o dispositivo das emendas parlamentares ao orçamento da União é amplamente utilizado pelos parlamentares do campo empírico analisado. A relação entre votação e emendas não pode ser descartada, mas é preciso criar outros indicadores para encontrar padrões nessa relação.

No que tange à discussão sobre paroquialismo ou distributivismo, os resultados sobre o comportamento dos deputados federais no que se refere à alocação de recursos aos entes federativos através das emendas orçamentárias individuais apontam alguns caminhos: a diferença entre o percentual de emendas apresentadas para o estado como todo, sem especificação a município determinado é bem representativa para os dois estados.

Desse modo, o significado de política distributiva estaria mais associado ao comportamento parlamentar que busca alocar recursos aos estados-membros em detrimento de interesses mais universais que seriam representados pela União. Isso indica que, outros flancos para pesquisa permitirá uma análise mais apurada. 
Performance eleitoral dos parlamentares e alocação de recursos nos municípios: efeito dos distritos informais 


\section{Referências}

ABRANCHES. Sergio. Presidencialismo Brasileiro: raízes e evolução do modelo político brasileiro. São Paulo: Companhia das Letras, 2018.

ABRANCHES. Sergio. Presidencialismo de coalizão: o dilema institucional brasileiro. Dados: Revista de Ciências Sociais, Rio de Janeiro, v. 31, n. 1, p. 3-55, 1988.

AMES. Barry. Os entraves da democracia no Brasil. Fundação Getúlio Vargas: Rio de Janeiro, 2003.

AMORIM NETO, Octavio. The presidential calculus: executive policy making and cabinet formation in the Americas. Comparative Political Studies, v. 39, n. 4, p. 415-440, May 2006.

BATISTA. Mariana. Taking Portfolios Difference Seriously: A Composite Measure Based on Policy, Office, and Budget in Brazil. Brazilian Political Science Review, v. 11, n.1, 2017.

BERTHOLINI, F.; PEREIRA, C. Pagando o preço de governar: custos de gerência de coalizão no presidencialismo brasileiro. In: ENCONTRO ANUAL DA AMERICAN POLITICAL SCIENCE ASSOCIATION - APSA, Washington, 2017.

BORGES, André. Federalismo, dinâmica eleitoral e políticas públicas no Brasil: uma tipologia e algumas hipóteses. Sociologias, Porto Alegre, v. 12, n. 24, p. 120-157, maio/ago. 2010.

BRASIL. Senado Federal. Siga Brasil. Disponível em: https://www12.senado.leg.br/. Acesso em: 11 maio 2019.

BRASIL. Tribunal Superior Eleitoral. Site institucional. Disponível em: http://www.tse.jus.br/eleitor/estatisticas-de-eleitorado/consulta-por-municipio-zona. Acesso em: 10 maio 2019.

CARVALHO, Nelson Rojas. E no início eram as bases: geografia política do voto e comportamento legislativo no Brasil. Rio de Janeiro: Revan, 2003. 224p.

FIGUEIREDO, A C; LIMONGI, F. Congresso Nacional: Organização, Processo legislativo e Produção Legal. Cadernos de Pesquisa, n. 5, p.23-34, 1996.

FIGUEIREDO, A C; LIMONGI, F. Executivo e legislativo na Nova ordem Constitucional. Rio de janeiro: Fundação Getúlio Vargas, 1999. 108 p. v. 1.

FIGUEIREDO, A C; LIMONGI, F. Incentivos eleitorais, partidos e política orçamentária. Dados: Revista de Ciências Sociais, Rio de Janeiro, v. 45, n. 2, p. 303-344, 2002.

LANDMAN, Todd. Issues and Methods in Comparative Politics. $2^{\text {nd }}$ ed. New York: Routledge, 2003.

LIMONGI, F M P. Novo institucionalismo e os estudos legislativos: a literatura norteamericana recente. Bib: Boletim Informativo e Bibliográfico de Ciências Sociais, Rio de Janeiro, n. 37, p. 1-100, 1994.

MAINWARING. Scott. Políticos, partidos e sistemas eleitorais. Novos Estudos. Cebrap, n. 29, p. 34-58, mar. 1991. 
MAYHEW, D R. Congress: The electoral Connection. New Haven: Yale University Press, 1974.

NICOLAU, Jairo. Representantes de quem? Os (des)caminhos do seu voto da urna à Câmara dos Deputados. Rio de Janeiro: Zahar, 2017.

PEREIRA, Carlos; MUELLER, Bernardo. Comportamento estratégico em presidencialismo de coalizão: As relações entre Executivo e Legislativo na elaboração do orçamento brasileiro. Dados: Revista de Ciências Sociais, Rio de Janeiro, v. 45, n. 22, p. 45-67, 2002.

PEREIRA, Carlos; MUELLER, Bernardo. The cost of governing strategic behavior of the president and legislators in Brazil's budgetary process. Comparative Political Studies, v. 37, n. 7, p. 781-815, 2004.

PEREIRA, Carlos; MUELLER, Bernardo. Partidos Fracos na Arena Eleitoral e Partidos Fortes na Arena Legislativa: A Conexão Eleitoral no Brasil. Dados: Revista de Ciências Sociais, Rio de Janeiro, vol. 46, n. 4, 2003, pp. 735 - 771.

Artigo submetido em: 2020-04-04

Artigo reapresentado em: 2020-05-10

Artigo aceito em:2020-05-19 